\title{
Guidelines
}

European

Thyroid Journal
Eur Thyroid J 2018;7:167-186

DOI: $10.1159 / 000490384$
Received: April 26, 2018

Accepted after revision: May 24, 2018

Published online: July 25, 2018

\section{European Thyroid Association Guideline for the Management of Graves' Hyperthyroidism}

\author{
George J. Kahaly ${ }^{\mathrm{a}}$ Luigi Bartalena ${ }^{\mathrm{b}}$ Lazlo Hegedüs ${ }^{c}$ Laurence Leenhardt ${ }^{d}$ \\ Kris Poppe ${ }^{e}$ Simon H. Pearce ${ }^{f}$ \\ ${ }^{a}$ Department of Medicine I, Johannes Gutenberg University (JGU) Medical Center, Mainz, Germany; ${ }^{b}$ Department of \\ Medicine and Surgery, University of Insubria, Varese, Italy; ' $D$ Department of Endocrinology and Metabolism, Odense \\ University Hospital, Odense, Denmark; ${ }^{\mathrm{d}}$ Thyroid and Endocrine Tumors Unit, Pitié Salpêtrière Hospital, Sorbonne \\ University, Paris, France; ${ }^{e}$ Endocrine Unit, CHU Saint-Pierre, Université Libre de Bruxelles (ULB), Brussels, Belgium; \\ fDepartment of Endocrinology, Institute of Genetic Medicine, Newcastle University, Newcastle upon Tyne, UK
}

\section{Keywords}

Graves' hyperthyroidism · Management · Antithyroid drugs . Radioiodine therapy · Thyroidectomy · Graves' orbitopathy

\begin{abstract}
Graves' disease (GD) is a systemic autoimmune disorder characterized by the infiltration of thyroid antigen-specific $T$ cells into thyroid-stimulating hormone receptor (TSH-R)-expressing tissues. Stimulatory autoantibodies (Ab) in GD activate the TSH-R leading to thyroid hyperplasia and unregulated thyroid hormone production and secretion. Diagnosis of GD is straightforward in a patient with biochemically confirmed thyrotoxicosis, positive TSH-R-Ab, a hypervascular and hypoechoic thyroid gland (ultrasound), and associated orbitopathy. In GD, measurement of TSH-R-Ab is recommended for an accurate diagnosis/differential diagnosis, prior to stopping antithyroid drug (ATD) treatment and during pregnancy. Graves' hyperthyroidism is treated by decreasing thyroid hormone synthesis with the use of ATD, or by reducing the amount of thyroid tissue with radioactive io-
\end{abstract}

dine (RAI) treatment or total thyroidectomy. Patients with newly diagnosed Graves' hyperthyroidism are usually medically treated for 12-18 months with methimazole (MMI) as the preferred drug. In children with GD, a 24- to 36-month course of $\mathrm{MMI}$ is recommended. Patients with persistently high TSH-R-Ab at 12-18 months can continue MMI treatment, repeating the TSH-R-Ab measurement after an additional 12 months, or opt for therapy with RAI or thyroidectomy. Women treated with MMI should be switched to propylthiouracil when planning pregnancy and during the first trimester of pregnancy. If a patient relapses after completing a course of ATD, definitive treatment is recommended; however, continued long-term low-dose MMI can be considered. Thyroidectomy should be performed by an experienced high-volume thyroid surgeon. RAI is contraindicated in Graves' patients with active/severe orbitopathy, and steroid prophylaxis is warranted in Graves' patients with mild/active orbitopathy receiving RAI.
(C) 2018 European Thyroid Association Published by S. Karger AG, Basel

\section{KARGER}

E-Mail karger@karger.com www.karger.com/etj (c) 2018 European Thyroid Association

Published by S. Karger AG, Basel
Prof. George J. Kahaly

JGU Medical Center

DE-55101 Mainz (Germany)

E-Mail george.kahaly@unimedizin-mainz.de 


\section{Epidemiology and Pathogenesis}

Hyperthyroidism occurs due to an inappropriately high synthesis and secretion of thyroid hormone (TH) by the thyroid [1]. TH increases tissue thermogenesis and the basal metabolic rate, and reduces serum cholesterol levels and systemic vascular resistance. The complications of untreated hyperthyroidism include weight loss, osteoporosis, fragility fractures, atrial fibrillation, embolic events, and cardiovascular dysfunction [2-4]. The prevalence of hyperthyroidism is 1.2-1.6, 0.5-0.6 overt and $0.7-1.0 \%$ subclinical $[1,5]$. The most frequent causes are Graves' disease (GD) and toxic nodular goiter. GD is the most prevalent cause of hyperthyroidism in iodinereplete geographical areas, with 20-30 annual cases per 100,000 individuals [6]. GD occurs more often in women and has a population prevalence of $1-1.5 \%$. Approximately $3 \%$ of women and $0.5 \%$ of men develop GD during their lifetime [7]. The peak incidence of GD occurs among patients aged 30-60 years, with an increased incidence among African Americans [8].

GD is an organ-specific autoimmune disease whose major manifestations are owing to circulating autoantibodies $(\mathrm{Ab})$ that stimulate the thyroid-stimulating hormone receptor (TSH-R) leading to hyperthyroidism and goiter. TSH-R-stimulating $\mathrm{Ab}$ are predominantly of the IgG1 isotype and bind to a discontinuous epitope in the leucine-rich domain of the TSH-R extracellular domain, bounded roughly by amino acids 20-260 $[9,10]$. TSH-R also interacts with IGF1 receptors (IGF1R) on the surface of thyrocytes and on orbital fibroblasts, with the $\mathrm{TSH}-\mathrm{R}-\mathrm{Ab}$ interaction with TSH-R activating both IGF1R downstream pathways and TSH-R signaling [11]. Circulating stimulatory TSH-R-Ab binding to the TSH-R enhance the production of intracellular cyclic AMP, leading to the release of TH and thyrocyte growth. About $30 \%$ of GD patients have family members who also have GD or Hashimoto's thyroiditis. Twin studies have shown that $80 \%$ of the susceptibility to GD is genetic [12]. There are well-established associations between alleles of the major histocompatibility complex with GD, with susceptibility being carried with HLADR3 and HLA-DR4 haplotypes [13]. Other susceptibility loci at which association has been replicated include those at cytotoxic T lymphocyte antigen-4, protein tyrosine phosphatase nonreceptor-22, basic leucine zipper transcription factor 2, and CD40 [14]. A noncoding variant within the TSH-R gene itself also confers susceptibility. Environmental factors, such as cigarette smoking, high dietary iodine intake, stress, and pregnancy, also predispose to GD [15-17]. Oral contraceptive pill use appears protective, as is male sex, suggesting a strong influence of sex hormones $[6,15]$.

\section{Methodology}

The development of this guideline was commissioned by the Executive Committee (EC) and Publication Board of the European Thyroid Association (ETA), which selected a chairperson (G.J.K.) to lead the task force. Subsequently, in consultation with the ETA EC, G.J.K. assembled a team of European clinicians who authored this manuscript. Membership on the panel was based on clinical expertise, scholarly approach, representation of endocrinology and nuclear medicine, as well as ETA membership. The task force examined the relevant literature using a systematic PubMed search supplemented with additional published materials. An evidence-based medicine approach that incorporated the knowledge and experience of the panel was used to develop the text and a series of specific recommendations. The strength of the recommendations and the quality of evidence supporting each was rated according to the approach recommended by the Grading of Recommendations, Assessment, Development, and Evaluation (GRADE system) [18]. The ETA task force for this guideline used the following coding system: (a) strong recommendation indicated by 1 , and (b) weak recommendation or suggestion indicated by 2. The evidence grading is depicted as follows: $\bigcirc \bigcirc \bigcirc \varnothing$ denotes very-low-quality evidence; $\varnothing \varnothing \bigcirc \bigcirc$, low quality; $\varnothing \varnothing \varnothing \bigcirc$, moderate quality; $\varnothing \varnothing \varnothing \varnothing$, high quality. The draft was discussed by the task force, and then posted on the ETA website for 4 weeks for critical evaluation by the ETA members.

\section{Diagnosis}

\section{Serology}

Serum TSH measurement has the highest sensitivity and specificity of any single blood test used in the evaluation of suspected hyperthyroidism and should be used as an initial screening test $[19,20]$. However, when hyperthyroidism is strongly suspected, diagnostic accuracy improves when both a serum TSH and free T4 are assessed at the time of the initial evaluation. The relationship between free T4 and TSH (when the pituitary-thyroid axis is intact) is an inverse log-linear relationship; therefore, small changes in free T4 result in large changes in serum 


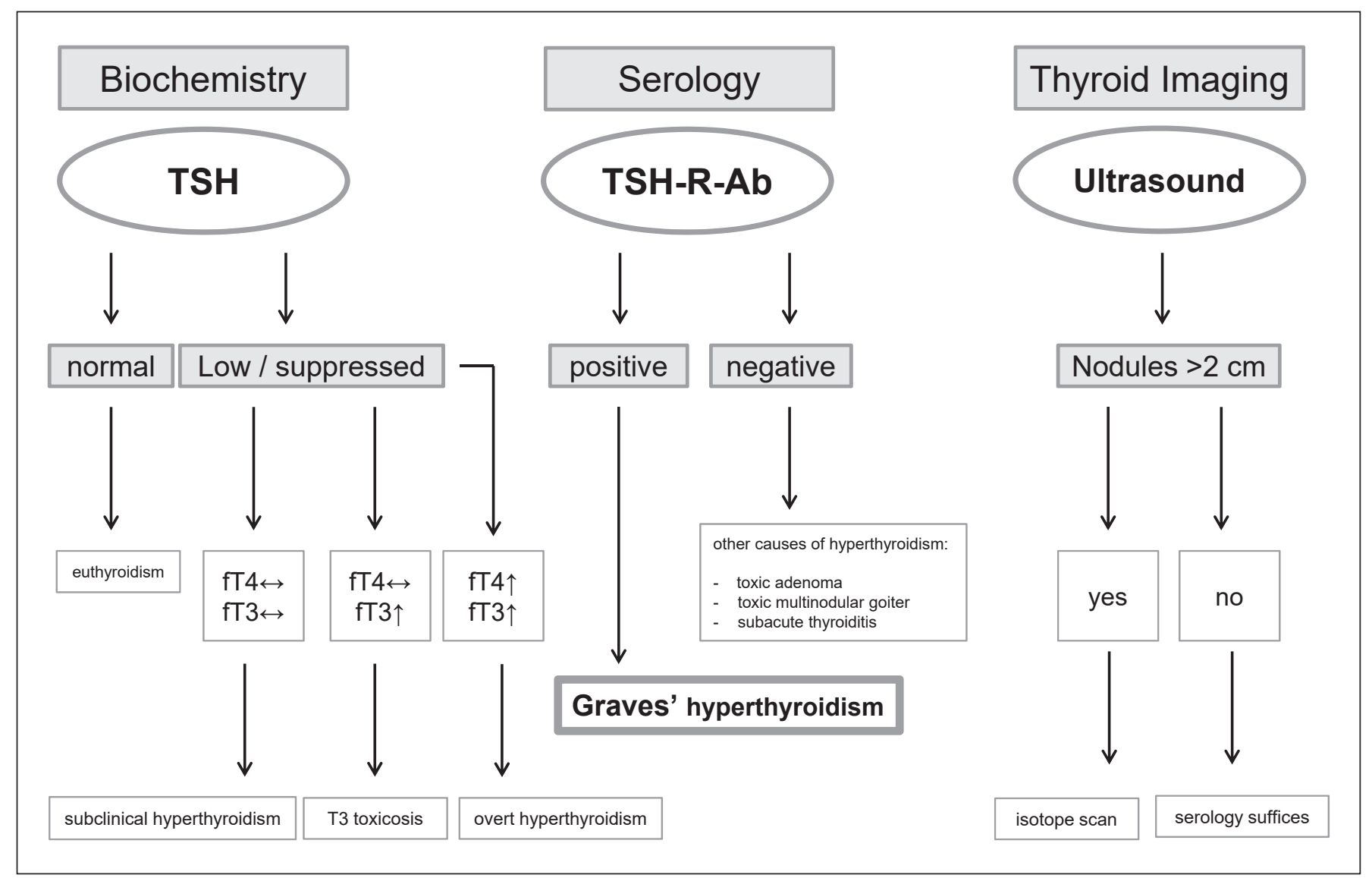

Fig. 1. Algorithm for investigating a patient with suspected Graves' hyperthyroidism.

TSH concentrations. Serum TSH levels are considerably more sensitive than direct TH measurements for assessing $\mathrm{TH}$ excess $[20,21]$. In overt hyperthyroidism, both serum free T4 and T3 concentrations are elevated, and serum TSH is suppressed; however, in milder hyperthyroidism, serum total T4 and free T4 levels can be normal, only serum free T3 may be elevated, with an undetectable serum TSH (Fig. 1).

TSH-R-Ab are specific biomarkers for GD $[2,22]$. Most immunoassays today use a competitive-binding assay and measure what are referred to as TSH-R binding inhibitory immunoglobulins (TBII). Binding assays only report the presence or absence of TSH-R-Ab and their concentrations, but do not indicate their functional activity $[23,24]$. A meta-analysis of 21 studies showed that the overall pooled sensitivity and specificity of the serum TSH-R-Ab concentration measured with second- and third-generation binding assays were 97 and 98\%, respectively [25]. In contrast, the highly sensitive cell-based bio- assays [26-33] exclusively differentiate between the TSHR-stimulating Ab (TSAb) and TSH-R-blocking Ab [34, 35]. Also, TSAb is a highly sensitive and predictive biomarker for the extrathyroidal manifestations of GD [3642] as well as a useful predictive measure of fetal or neonatal hyperthyroidism $[43,44]$. Finally, the incorporation and early utilization of TSAb into current diagnostic algorithms conferred a $46 \%$ shortened time to diagnosis of GD and a cost saving of $47 \%$ [45].

\section{Recommendations}

1 The measurement of TSH-R-Ab is a sensitive and specific tool for rapid and accurate diagnosis and differential diagnosis of Graves' hyperthyroidism. 1, $\varnothing \varnothing \varnothing \varnothing$

2 When technically available, differentiation of TSH-R$\mathrm{Ab}$ functionality is helpful and predictive in Graves' patients during pregnancy/postpartum, as well as for extrathyroidal manifestations. $2, \varnothing \varnothing \varnothing \bigcirc$ 


\section{Imaging}

Considerable inter- and intraregional variation in diagnostic practice has been reported for GD [22]. In addition to thyroid function and TSH-R-Ab determination, most clinicians would request thyroid ultrasound (US) and less often isotope scanning [22]. In a study conducted among 263 endocrinologists in 992 hyperthyroid patients, thyroid US and scintigraphy were used in 93.8 and $40.3 \%$, respectively [46]. Ordinarily, there is no indication for CT scan, MRI, or PET-CT of the thyroid gland. Thyroid US is a convenient, noninvasive, rapid, and accurate tool in the initial work-up of GD patients. It aids in the diagnosis, without exposing the patient to ionizing irradiation, and assists in determining the underlying etiology of thyrotoxicosis and detecting concomitant thyroid nodules [47-49]. Imaging results are highly dependent on equipment and the experience of the investigator. A high-frequency linear probe should be used. GD is often, but not invariably, characterized by diffuse thyroid enlargement and by hypoechogenicity, both assessed by US and conventional grey scale analysis [6].

A color-flow or power Doppler examination characterizes vascular patterns and quantifies thyroid vascularity [50]. The latter is significantly increased in untreated GD and typically shows a pulsatile pattern called "thyroid inferno" that is multiple small areas of increased intrathyroidal flow seen diffusely throughout the gland [51]. Accurate measurement of thyroid artery flow velocity and peak systolic velocity (PSV) requires adjustments of pulse repetition frequency of wall filters and control of the insonation angle at between 0 and $60^{\circ}$. In untreated GD, thyroidal artery flow velocity and PSV are significantly increased. The PSV can differentiate between thyrotoxicosis owing to GD from subacute thyroiditis or amiodarone-induced thyrotoxicosis type 2, where the blood flow is reduced [52]. Typical US patterns combined with positive TSH-R-Ab obviate the need for scintigraphy in the vast majority of cases. However, thyroid scintigraphy may be useful in the assessment of patients prior to radioactive iodine (RAI) treatment, especially when facing coexistent multinodular goiter [6].

Recommendations

3 US examination, comprising conventional grey scale analysis and color-flow or power Doppler examination is recommended as the imaging procedure to support the diagnosis of Graves' hyperthyroidism. 1, $\varnothing \varnothing \varnothing \varnothing$

4 Scintigraphy of the thyroid is suggested when thyroid nodularity coexists with hyperthyroidism, and prior to

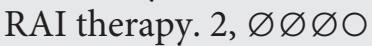

Table 1. Mechanism of action of antithyroid drugs

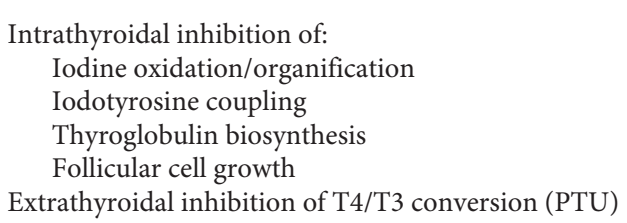

\section{Management}

\section{Medical Treatment}

Graves' hyperthyroidism is treated by reducing TH synthesis, using ATD, or by reducing the amount of thyroid tissue with RAI treatment or total thyroidectomy [6, 47]. ATD represent the predominant therapy in Europe, Asia, and in the meantime in the USA $[53,54]$. The main ATD are thionamides, such as propylthiouracil (PTU), carbimazole (CBZ), and the active metabolite of the latter, methimazole (MMI). CBZ is not an active substance; it has to be decarboxylated to MMI in the liver. Thionamides inhibit the coupling of iodothyronines and hence reduce the biosynthesis of TH [55]. All inhibit the function of thyroperoxidase, reducing oxidation and the organification of iodide (Table 1). ATD are indicated as a first-line treatment of GD, particularly in younger subjects, and for short-term treatment of GD before RAI therapy or thyroidectomy $[2,6,22]$. ATD reduce TSH-R$\mathrm{Ab}$ levels and enhance rates of remission compared to no therapy. PTU at higher doses inhibits deiodination of T4 to T3 [56]. However, this effect is of minor benefit, except in severe thyrotoxicosis, and is offset by the much shorter half-life of this drug compared to MMI (Table 2). The initial dose of MMI is usually $10-30 \mathrm{mg}$ once daily depending on the severity of hyperthyroidism (CBZ 15-40 $\mathrm{mg} /$ day). PTU is given at a dose of $100 \mathrm{mg}$ every $8 \mathrm{~h}$, and divided doses are given throughout the course. The starting dose of ATD can be gradually reduced (titration regimen) as thyrotoxicosis improves. Thyroid function tests are reviewed 3-4 weeks after starting treatment, and the dose is titrated based on free T4 and free T3 levels. A substantial proportion of patients reach euthyroidism within 3-4 weeks of treatment. TSH levels often remain suppressed for several months and therefore do not provide a sensitive index of early treatment response. The usual daily maintenance doses of ATD in the titration regimen are 2.5-10 mg of MMI and 50-100 mg of PTU. Alternatively, MMI daily doses of $30 \mathrm{mg}$ may be given combined with levothyroxine (L-T4) supplementation (block and 
Table 2. Pharmacology and pharmacokinetics of antithyroid drugs

\begin{tabular}{lll}
\hline & MMI & PTU \\
\hline Absorption & rapid & rapid \\
Bioavailability & $\sim 100 \%$ & $\sim 100 \%$ \\
Peak serum level & $60-120 \mathrm{~min}$ & $60 \mathrm{~min}$ \\
Serum half-life & $6-8 \mathrm{~h}$ & $90 \mathrm{~min}$ \\
Thyroid concentration & $5 \times 10^{5} \mathrm{~mol} / \mathrm{L}$ & unknown \\
Thyroid turnover & slow & moderate \\
Duration of action & $>24 \mathrm{~h}$ & $8-12 \mathrm{~h}$ \\
Serum protein binding & nil & $>75 \%$ \\
Crosses placenta & ++ & + \\
Levels in breast milk & ++ & + \\
Volume of distribution & $40 \mathrm{~L}$ & $20 \mathrm{~L}$ \\
Excretion & renal & renal \\
Metabolism during illness & & \\
$\quad$ Renal & nil & nil \\
$\quad$ Liver & prolonged & nil \\
Potency & $10 \times$ & $1 \times$ \\
Normalization T3/T4 & $6 \mathrm{weeks}$ & $12 \mathrm{weeks}$ \\
Adverse events & $15 \%$ & $20 \%$ \\
Agranulocytosis & $0.6 \%$ & $1-1.5 \%$ \\
Cross-reaction of adverse events & $13.8 \%$ & $15.2 \%$ \\
Compliance & high & fair \\
Costs & low & moderate \\
\hline
\end{tabular}

MMI, methimazole; PTU, propylthiouracil.

replace regimen) to avoid drug-induced hypothyroidism. Initial reports suggesting superior remission rates with the block-replace regimen have not been reproduced [2, 57]. The titration regimen is often preferred to minimize the dose of ATD.

The optimal duration of ATD therapy for the titration regimen is 12-18 months [57]. Continued L-T4 treatment following initial ATD therapy does not provide any benefit in terms of the recurrence of hyperthyroidism [5, 57]. Maximum remission rates (50-55\%) are achieved within 12-18 months. Measurement of TSH-R-Ab levels prior to stopping ATD therapy is recommended, as it aids in predicting which patients can be weaned from the medication, with normal levels indicating a greater chance of remission [5,22]. Monitoring the titers of functional stimulatory and blocking TSH-R-Ab during treatment help in predicting the outcome $[58,59]$. Patients with persistently high TSH-R-Ab at 12-18 months can continue MMI therapy, repeating the TSH-R-Ab measurement after an additional 12 months, or opt for RAI or thyroidectomy (Fig. 2). In line with this, arguments for an extended use of ATD in both adults and children with
GD have been published [60-62]. Relapse is most likely within the first 6-12 months after ATD withdrawal, but may occur years later. Patients with severe hyperthyroidism, large goiters, or persistent high titers of TSH-R-Ab are most likely to relapse when treatment stops, but the outcome is difficult to predict. All patients should be followed closely for relapse during the first year after treatment and at least annually thereafter.

\section{Recommendations}

5 Patients with newly diagnosed Graves' hyperthyroidism should be treated with ATD. RAI therapy or thyroidectomy may be considered in patients who prefer this approach. $1, \varnothing \varnothing \varnothing \varnothing$

6 MMI (CBZ) should be used in every non-pregnant patient who chooses ATD therapy for Graves' hyperthyroidism. 1, $\varnothing \varnothing \varnothing \varnothing$

7 MMI is administered for $12-18$ months then discontinued if the TSH and TSH-R-Ab levels are normal. 1, $\varnothing \varnothing \varnothing \varnothing$

8 Measurement of TSH-R-Ab levels prior to stopping ATD therapy is recommended, as it aids in predicting which patients can be weaned from the medication, with normal levels indicating a greater chance of remission. $1, \varnothing \varnothing \varnothing \varnothing$

9 Patients with persistently high TSH-R-Ab at 12-18 months can continue MMI therapy, repeating the TSH-R-Ab measurement after an additional 12 months, or opt for RAI or thyroidectomy. $1, \varnothing \varnothing \varnothing \bigcirc$

\section{Adverse Events}

Common side effects of ATD (Table 3) are rash, urticaria, and arthralgia (1-5\%). Minor cutaneous reactions are managed with concurrent antihistamine therapy without stopping the ATD. These may resolve spontaneously or after substituting an alternative ATD [56]. In the case of a serious allergic reaction, prescribing the alternative drug is not recommended. Rare but major side effects [63] include hepatitis, a lupus-like syndrome, and agranulocytosis (neutrophil count $<500 / \mathrm{mL}$ ), which occurs in $0.1-1.0 \%$ of cases $[64,65]$. Agranulocytosis tend to occur abruptly within 3 months after the initiation of ATD therapy [65]. The cumulative incidence of ATD-induced agranulocytosis and pancytopenia at 100 and 150 days after the initiation of ATD was 0.28 and $0.29 \%$, respectively [66]. Genetic determinants of ATD-induced agranulocytosis [67] have shown that the alleles HLA-B*38:02 and HLA-DRB $1 * 08: 03$ are independent susceptibility loci for agranulocytosis. Carrying both HLA-B*38:02 and HLA-DRB1*08:03 increases the odds ratio to 48.41 (95\% 


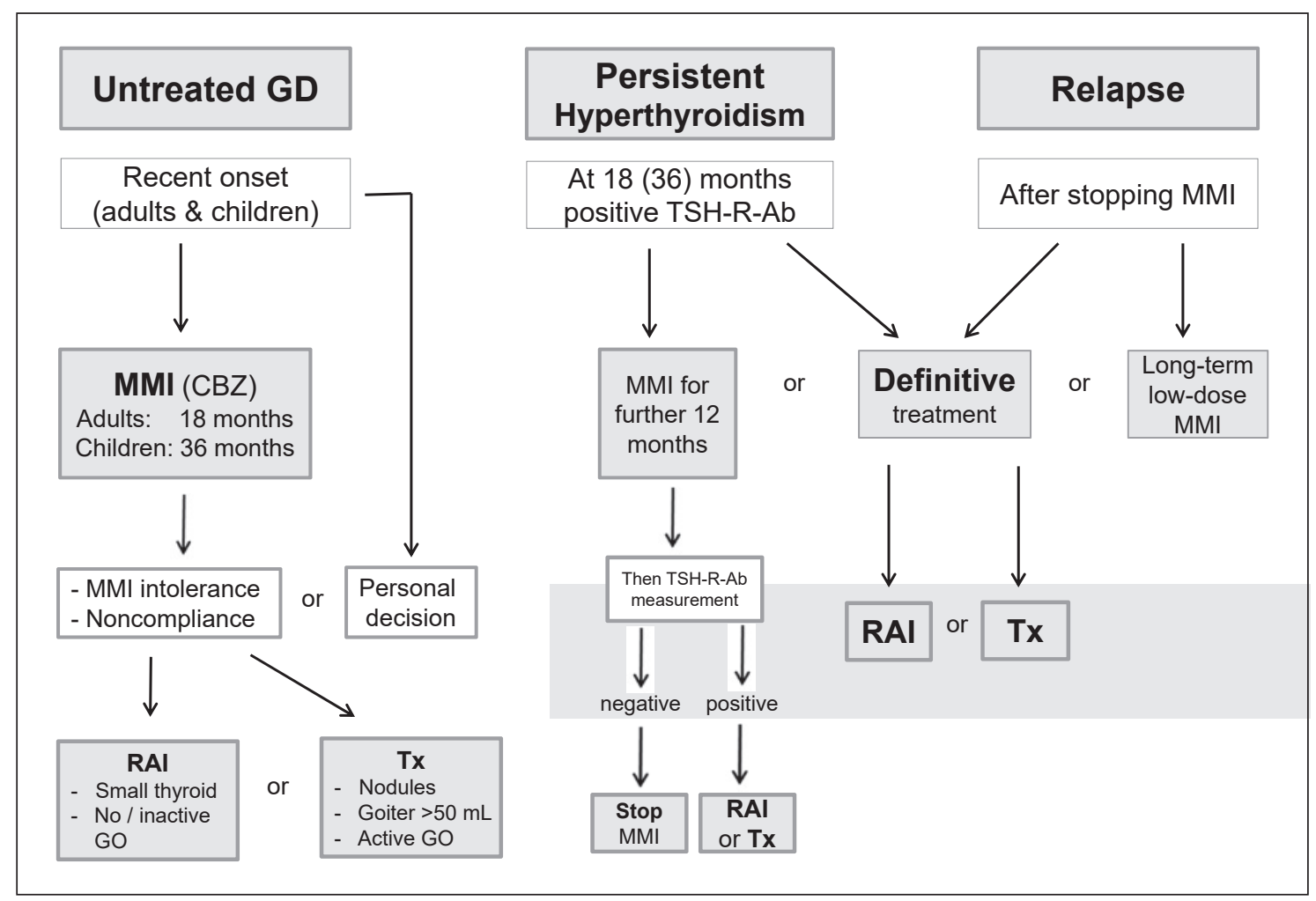

Fig. 2. Algorithm for the management of a patient with Graves' hyperthyroidism. GD, Graves' disease; MMI, methimazole; CBZ, carbimazole; GO, Graves' orbitopathy; RAI, radioactive iodine; Tx, total thyroidectomy.

Table 3. Adverse events of antithyroid drugs

\author{
Common (1.0-5.0\%) \\ Skin rash \\ Urticaria \\ Arthralgia, polyarthritis \\ Fever \\ Transient mild leukopenia \\ Rare $(0.2-1.0 \%)$ \\ Gastrointestinal \\ Abnormalities of taste and smell \\ Agranulocytosis \\ Very rare $(<0.1 \%)$ \\ Aplastic anemia (PTU, CBZ) \\ Thrombocytopenia (PTU, CBZ) \\ Vasculitis, lupus-like, ANCA+ (PTU) \\ Hepatitis (PTU) \\ Hypoglycemia (anti-insulin Abs; PTU) \\ Cholestatic jaundice (CBZ/MMI)
}

PTU, propylthiouracil; MMI, methimazole; CBZ, carbimazole; ANCA, antineutrophil cytoplasmic antibody.

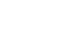

CI 21.66-108.22). In Caucasians, a different HLA-B allele (B*27:05; OR 7.3, 95\% CI 3.81-13.96) and rare NOX3 variants have been tentatively associated $[68,69]$.

MMI (CBZ) and PTU exert dissimilar incidence rates of hepatotoxicity. PTU-associated hepatotoxicity occurs foremost in children in contrast to that associated with MMI, which is usually milder with a cholestatic pattern [70]. In a study comprising 71,379 ATD initiators [71], MMI was associated in a dose-dependent manner with an increased risk for hepatitis and cholestasis. ATD are stopped and not restarted if a patient develops major side effects. Patients should be given written instructions regarding the symptoms of possible agranulocytosis (e.g., sore throat, fever, mouth ulcers) and the need to stop treatment pending a complete blood count. The use of routine hematological and liver function tests is not useful, as the onset of agranulocytosis is abrupt [56].

\section{Recommendations}

10 Patients should be informed of potential side effects of ATD and the necessity of informing the physician promptly if they should develop jaundice, light-col-
Kahaly/Bartalena/Hegedüs/Leenhardt/ Poppe/Pearce


ored stools, dark urine, fever, pharyngitis, or cystitis. $1, \varnothing \varnothing \bigcirc \bigcirc$

11 In patients taking ATD, a differential white blood cell count should be obtained during febrile illness and/or pharyngitis, and liver function should be assessed in those who experience jaundice, light-colored stools, or dark urine. $1, \varnothing \varnothing \bigcirc \bigcirc$

\section{Beta-Adrenergic Blockade}

Propranolol (20-40 mg every $6 \mathrm{~h}$ ) or longer acting beta-blockers (i.e., atenolol/bisoprolol), are useful to control adrenergic symptoms such as palpitations and tremor, especially in the early stages before ATD take effect. High doses of propranolol ( $40 \mathrm{mg} 4$ times daily) inhibit peripheral conversion of T4 to T3. Cardioselective betablockers with higher cardioprotective effects and superior prevention of atrial fibrillation represent an alternative choice, especially for patients with asthma. Anticoagulation with warfarin or direct oral anticoagulants should be considered in all patients with atrial fibrillation. If digoxin is used, increased doses are often needed in the thyrotoxic state $[2,5,6,72]$.

Recommendation

12 Beta-adrenergic blockade is recommended in all suitable patients with Graves' hyperthyroidism. 1, $\varnothing \varnothing \varnothing \varnothing$

\section{Relapse after a Course of ATD Treatment}

A meta-analysis [73] has confirmed the high relapse rate following ATD therapy (52.7\%) in comparison with RAI (15\%, OR 6.25) or surgery (10\%, OR 9.09), along with a significant side-effect profile for these drugs (13\%). Another meta-analysis evaluating 54 trials and 7,595 participants showed several risk factors predicting persistence (49\%) in GD [74]. Orbitopathy, smoking, thyroid volume, free T4, total T3, and TSH-R-Ab were significantly associated with relapse. In a prospective study introducing the quantitative predictive "GREAT" score for GD [75], 37\% of patients with a first episode of Graves' hyperthyroidism relapsed within 2 years after ATD withdrawal. Lower age, higher serum TSH-R-Ab and free T4, larger goiters at diagnosis, $\mathrm{PTPN} 22 \mathrm{C} / \mathrm{T}$ polymorphism, and HLA subtypes DQB $1 * 02$, DQA $1 * 05$, and $\mathrm{DRB} 1{ }^{*} 03$ were independent predictors for recurrence.

On the other hand, the benefits of long-term ATD treatment after recurrence were shown in patients with GD relapse after the discontinuation of ATD therapy for 12-24 months [76]. Either RAI treatment and L-T4 replacement or MMI (2.5-7 mg/daily) were used. No notable side effects were observed. Thyroid dysfunction was predominant in the RAI group $(p<0.001)$, and euthyroidism was more common in the MMI group $(p<0.001)$. Graves' orbitopathy (GO) deterioration was higher postRAI $(p<0.0005)$ over all periods of follow-up (OR 21.1, $95 \%$ CI $1.5-298, p<0.0003)$. Patients gained more weight post-RAI $(p<0.005)$. Thus, low MMI doses were efficient, safe, and offered better outcomes for GO than RAI treatment. In another trial [77], long-term MMI treatment of GD was safe, while the complications and expenses of ATD did not exceed that of RAI.

\section{Recommendation}

13 If a patient with GD becomes hyperthyroid after completing a first course of ATD, definitive treatment with RAI or thyroidectomy is recommended. Continued long-term low-dose MMI can be considered in patients not in remission who prefer this approach. 1, $\varnothing \varnothing \varnothing$

\section{Subclinical Graves' Hyperthyroidism}

Endogenous mild or subclinical hyperthyroidism (SH) is associated with increased risk of coronary heart disease mortality, incident atrial fibrillation, heart failure, fractures, and excess mortality in patients with serum TSH levels $<0.1 \mathrm{mIU} / \mathrm{L}$ [78-82]. In addition, in the presence of TSH-R-Ab indicating "subclinical" GD, the rate of progression to overt hyperthyroidism is up to $30 \%$ in the subsequent 3 years [83]. Therefore, despite the absence of randomized trials, treatment is indicated in patients older than 65 years with a TSH that is persistently $<0.1 \mathrm{mIU} / \mathrm{L}$ to potentially avoid these serious adverse events and the risk of progression to overt hyperthyroidism. Treatment might be considered in patients older than 65 years with TSH levels of 0.1-0.39 mIU/L because of their increased risk of atrial fibrillation, and might also be reasonable in younger ( $<65$ years) symptomatic patients with $\mathrm{TSH}<0.1$ $\mathrm{mIU} / \mathrm{L}$ because of the risk of progression, especially in the presence of risk factors or comorbidity.

Recommendations

14 Treatment of SH is recommended in Graves' patients $>65$ years with serum TSH levels that are persistently $<0.1 \mathrm{mIU} / \mathrm{L} .1, \varnothing \varnothing \bigcirc \bigcirc$

15 ATD should be the first choice of treatment of Graves' SH. $1, \varnothing \varnothing \bigcirc \bigcirc$

\section{Thyroid Storm}

With a mortality rate estimated at $10 \%$, the life-threatening thyroid storm demands a rapid diagnosis and emergency treatment $[84,85]$. The condition manifests 
as decompensation of multiple organs with impaired consciousness, high fever, heart failure, diarrhea, and jaundice. Diagnostic criteria for thyroid storm in patients with severe Graves' thyrotoxicosis include hyperpyrexia, tachycardia, arrhythmia, congestive heart failure, agitation, delirium, psychosis, stupor, coma, nausea, vomiting, diarrhea, hepatic failure, and the presence of an identified precipitant [86]. The "Burch-Wartofsky Point Scale" system grades the severity of individual manifestations, with a point total of $\geq 45$ consistent with thyroid storm, 25-44 points classified as impending thyroid storm, and $<25$ points indicating that thyroid storm as unlikely. Nationwide surveys in Japan have revealed the high morbidity and mortality rates of this condition and have subsequently offered a multimodality treatment, including intravenous MMI or PTU (40 or $400 \mathrm{mg}$ every $8 \mathrm{~h}$ ), glucocorticoids (methylprednisolone $50 \mathrm{mg}$ i.v.), beta-blockers (propranolol $40 \mathrm{mg}$ every $6 \mathrm{~h}$ ), and monitoring in an intensive care unit [87]. The most common cause of death from thyroid storm was multiple organ failure, followed by heart and respiratory failure, arrhythmia, disseminated intravascular coagulation, gastrointestinal perforation, hypoxic brain syndrome, and sepsis [88].

\section{Recommendation}

16 A multimodality treatment approach to GD patients with thyroid storm should be used, including ATD therapy, glucocorticoid administration, beta-adrenergic blockade, cooling blankets, volume resuscitation, nutritional support, respiratory care, and monitoring in an intensive care unit. $1, \varnothing \varnothing \bigcirc \bigcirc$

\section{RAI Treatment}

RAI has been used since 1941; however, there have been few well-designed prospective trials, leaving many questions about indications, optimal dose, efficacy, and side-effects [89]. The cellular effect of the ionizing radiation leads to genetic damage, mutations, or cell death. The DNA damage from radiation is mediated via a combination of direct effects, through breakage of molecular bonds, or indirectly through the formation of free radicals. This leads to a decrease in thyroid function and/or reduction in thyroid size. There are neither good measures of individual radiosensitivity nor ideal methods of predicting the clinical response to RAI therapy.

\section{Indications and Applied RAI Dose}

Patients with side-effects to or recurrence after a course of ATD, cardiac arrhythmias, and thyrotoxic periodic pa- ralysis are candidates for RAI. Only one study has compared the ATD, surgery, and RAI head-to-head [90]. In that randomized study, the risk of relapse was highest after ATD, but there were no significant differences in sick leave or satisfaction with the therapy. There are contradictory reports pertaining to the cost effectiveness of GD treatment [91-94]. Some centers use RAI in pediatric patients, in which case ablative doses should be used with the aim of rapid hypothyroidism. Other side-effects are not different from those in adults [95]. RAI is contraindicated in pregnancy and during breast feeding, and conception should be postponed until at least 6 months after the therapy. There is no evidence of detrimental effects on long-term fertility, miscarriage, stillbirths, or congenital defects in the offspring [96]. The same 6-month period applies for males. ALARA (as low as reasonably achievable) is an important principle with radiation treatment, but an elusive goal when balancing rapid relief of hyperthyroidism and postponing hypothyroidism. Therefore, many have given up meticulous dose calculation and offer fixed activities of, for example, 185, 370, or $555 \mathrm{MBq}$, based on validated clinical parameters, such as thyroid size [89].

\section{Effect on Thyroid Function and Size}

Thyroid function is normalized within 3-12 months after RAI therapy in $50-90 \%$ of patients [89]. The patient should be informed that repeated doses of RAI may be needed. The incidence rate of hypothyroidism is $5-50 \%$ after the first year, and is positively associated with the thyroid RAI dose. This is followed by a yearly hypothyroidism rate of 3-5\%, which is largely independent of the RAI dose [97]. Even with low-dose RAI, which increases persistent/recurrent disease, hypothyroidism is inevitable [98]. Thyroid size is normalized within a year of RAI [97]. RAI is not contraindicated in large goiters, even if partially retrosternal or intrathoracic. ATD should be temporarily paused for a week before and after RAI therapy [99].

\section{Adverse Effects of RAI Therapy}

There may be thyroid pain, swelling, and sialoadenitis. GD is associated with increased morbidity and mortality $[100,101]$. Its treatment decreases mortality [102], while RAI per se does not increase mortality [89]. There is neither evidence of increased thyroid cancer nor total cancer mortality following RAI therapy [103]. Posttherapy thyroid storm is extremely rare, and in non-ATD-pretreated patients TH levels are normally not elevated post-RAI, but decline after a few days [104]. Transient hyperthy- 
Table 4. Advantages and disadvantages of total thyroidectomy for Graves' hyperthyroidism

\begin{tabular}{ll}
\hline Advantages & Disadvantages \\
\hline No recurrent hyperthyroidism & Risk of postoperative hypoparathyroidism \\
No radiation risk & Risk of recurrent nerve palsy \\
Rapid control of hyperthyroidism & Permanent hypothyroidism \\
No reported detrimental effect on the course of & Risks related to anesthesia or surgery \\
Graves' orbitopathy & Hospitalization \\
& Costs \\
& Permanent scar \\
\hline
\end{tabular}

roidism can be prevented by pre-RAI ATD treatment, but only if ATD are resumed post-RAI [105]. Posttherapy flare-up relates to high TSH-R-Ab levels. It is difficult to differentiate between treatment failure and transient hyperthyroidism. However, if thyrotoxicosis has not improved after 3 months, treatment failure is likely. Transient hypothyroidism is seen in $3-20 \%$ of cases and does not invariably lead to permanent hypothyroidism, but treatment with $\mathrm{TH}$ is generally recommended to avoid the development of or a flare-up of GO. De novo or flareup of GO is seen in 15-33\% of cases after RAI therapy [106]. Prophylactic glucocorticoids prevent this without influencing the ultimate outcome of thyroid function [107].

\section{Recommendations}

17 There are no absolute indications for RAI therapy, but it is often recommended for patients with side-effects to or recurrence after a course of ATD. $1, \varnothing \varnothing \bigcirc \bigcirc$

18 Verbal as well as written information on all aspects of efficacy and potential side-effects of RAI therapy should be provided. $1, \varnothing \varnothing \bigcirc \bigcirc$

19 If ATD are used before RAI therapy they should be paused around 1 week before and after therapy in order not to decrease the efficacy of RAI therapy. 1, $\varnothing \varnothing \varnothing \varnothing$

20 No dose calculation can secure long-term euthyroidism and it is fully acceptable to offer a fixed dose of RAI. $1, \varnothing \varnothing \varnothing 0$

21 Pregnancy and breast feeding constitute absolute contraindications to RAI therapy. $1, \varnothing \varnothing \varnothing 0$

22 Conception should be postponed until at least 6 months after RAI in both males and females. $1, \varnothing \varnothing \varnothing 0$

23 If used in children, ablative doses aiming at rapid hypothyroidism should be administered. $1, \varnothing \varnothing \bigcirc \bigcirc$

\section{Surgery}

Thyroidectomy is the least commonly selected treatment for newly diagnosed Graves' hyperthyroidism. In recent American and European questionnaire-based surveys, surgery represented the first-line treatment in $0.9 \%$ [108] and 2.1\% [22] of cases, respectively. However, thyroidectomy is an effective treatment when goiter is large, there is coincident primary hyperparathyroidism or suspicion of malignant nodules, the patient wishes to avoid exposure to ATD or RAI [109], or facilities for RAI treatment are not available [2]. Advantages of thyroidectomy include the absence of radiation risk, the rapid control of hyperthyroidism, and the usual absence of detrimental effects on GO (Table 4). However, thyroidectomy is a high-cost procedure requiring hospitalization, it bears an anesthetic and surgical risk, a permanent scar is left, and there may be complications. Similar to RAI, long-term L-T4 replacement therapy is required to maintain euthyroidism.

If surgery is selected, total thyroidectomy is the procedure of choice, because it bears the same risk of complications as bilateral subtotal thyroidectomy, while the rate of recurrent hyperthyroidism is lower [110, 111]. Whether thyroidectomy is more effective than RAI as a definitive treatment preventing relapses of hyperthyroidism is a matter of debate due to conflicting results of two systematic reviews - favoring thyroidectomy [110], or showing no significant differences between the two treatments [73].

To minimize the risk of complications (hypoparathyroidism, laryngeal nerve palsy, wound infection, hemorrhage), surgery should be performed by a skilled highvolume surgeon [112]. To minimize the risk of intra- or postoperative exacerbation of thyrotoxicosis, hyperthyroidism should be adequately controlled by ATD treatment prior to surgery [109]. The use of a saturated solution of potassium iodide (SSKI) is helpful in the immedi- 
ate preoperative period (10 days) to decrease thyroid vascularity and intraoperative blood loss [113]. However, this preparation is used by less than $40 \%$ of thyroidologists [22]. When thyroidectomy must be performed before an adequate control of hyperthyroidism is achieved, in addition to ATD, beta-blockers, glucocorticoids, and eventually SSKI may be helpful. Vitamin D deficiency should be corrected prior to surgery to reduce the risk of postoperative hypocalcemia [114].

\section{Recommendations}

24 If surgery is selected, total thyroidectomy is the procedure of choice, and should be performed by a skilled surgeon with high annual volumes of thyroidectomies. $1, \varnothing \varnothing \varnothing \varnothing$

25 Euthyroidism should be restored by ATD prior to surgery to avoid peri- or postoperative exacerbation of thyrotoxicosis. $1, \varnothing \varnothing \varnothing \varnothing$

26 Vitamin D deficiency should be corrected to reduce the postoperative risk of hypocalcemia. $1, \varnothing \varnothing \varnothing \varnothing$

27 A solution containing potassium iodide can be given for 10 days prior to surgery. $2, \varnothing \varnothing \varnothing \bigcirc$

\section{Treatment of Graves' Hyperthyroidism in Patients with Orbitopathy}

Thyroid dysfunction, both hyper- and hypothyroidism, can influence the course of GO. Accordingly, the ETA/EUGOGO guideline [115] and an Italian consensus statement [116] recommended that prompt restoration and stable maintenance of euthyroidism are priorities in patients with GO. How to manage hyperthyroidism when GO is present is, however, a challenging dilemma [117]. ATD per se do not influence the natural course of GO, but might be beneficial for GO indirectly, as a consequence of the restoration of euthyroidism $[118,119]$. Hypothyroidism can also cause the progression of GO [120]. RAI causes the progression or de novo occurrence of GO [119, $121,122]$, particularly in smokers [123], those with preexisting [119] and recent-onset GO [124], late correction of post-RAI hypothyroidism [125, 126], and high TSH-R$\mathrm{Ab}$ levels [127]. In patients at risk of RAI-associated GO occurrence or progression, oral low-dose steroid prophylaxis $[115,128]$ is effective, as shown by two RCTs [119, $121]$ and two meta-analyses $[129,130]$. Steroid prophylaxis can be avoided in patients with absent or inactive $\mathrm{GO}$ if other risk factors for RAI-associated progression of GO are absent $[115,130]$. Thyroidectomy does not seem to impact the natural history of GO $[122,131]$ (Table 5).
Table 5. Treatment of hyperthyroidism due to GD in the presence of GO

\begin{tabular}{llll}
\hline Degree of severity and activity of GO & ATD & RAI & Tx \\
\hline Mild and inactive & Yes & Yes $^{1}$ & Yes \\
Mild and active & Yes $^{2}$ & Yes $^{3}$ & Yes \\
Moderate-to-severe and inactive & Yes & Yes $^{1}$ & Yes \\
Moderate-to-severe and active & Yes & No & No \\
Sight threatening & Yes & No & No \\
\hline
\end{tabular}

ATD, antithyroid drugs; RAI, radioactive iodine; $\mathrm{Tx}$, total thyroidectomy; GD, Graves' disease; GO, Graves' orbitopathy.

${ }^{1}$ Steroid prophylaxis in selected cases.

${ }^{2}$ Selenium supplementation for 6 months.

${ }^{3}$ Steroid prophylaxis warranted (see text).

\section{Mild and Inactive}

Treatment for hyperthyroidism is unlikely to cause ocular changes and, therefore, is chosen irrespective of GO $[116,117]$. If RAI treatment is selected, steroid prophylaxis is not indicated unless other risk factors for GO progression exist [115]. Rehabilitative surgery may be required for cosmetic or functional reasons.

\section{Mild and Active GO}

Treatment of hyperthyroidism is mostly independent of GO and relies on established criteria [2]. There is no RCT evidence that the long-term outcome of GO of this degree is better using ATD than definitive treatment. Steroid prophylaxis is indicated if RAI treatment is employed [130]. If ATD treatment is chosen, a 6-month selenium supplementation improves mild and active GO and prevents its progression to more severe forms [132].

\section{Moderate-to-Severe and Inactive GO}

The choice of thyroid treatment is mostly independent of GO. If RAI is selected, steroid prophylaxis can be avoided if other risk factors for GO reactivation are absent [117].

\section{Moderate-to-Severe and Active GO}

Rapid correction of hyperthyroidism with ATD and stable maintenance of euthyroidism are, per se, beneficial for GO and therefore strongly recommended [60, 61, 115]. Thyroid ablation has been alternatively advocated [133]. Prompt therapy for GO is warranted.

\section{Sight-Threatening GO}

Sight-threatening GO is an endocrine emergency because of the risk of sight loss due to dysthyroid optic neu- 
ropathy and/or corneal breakdown. Hyperthyroidism must be treated with ATD and immediate treatment with high-dose intravenous steroids is imperative with subsequent orbital decompression if response to steroids is inadequate within 2-4 weeks [115].

Recommendations

28 In patients with GO, hyperthyroidism should be promptly controlled by ATD, and euthyroidism stably maintained. $1, \varnothing \varnothing \varnothing \varnothing$

29 Patients treated with RAI should receive steroid prophylaxis if mild and active GO preexists or there are risk factors for RAI-associated GO occurrence or progression. $1, \varnothing \varnothing \varnothing \varnothing$

30 In patients with moderate-to-severe and active GO, treatment of GO should be the priority. Euthyroidism should be promptly restored with ATD and stably maintained. $1, \varnothing \varnothing \varnothing \varnothing$

31 Patients with sight-threatening GO should be treated with ATD. $1, \varnothing \varnothing \bigcirc \bigcirc$

32 Treatment for hyperthyroidism in patients with inactive GO can be selected independently of GO. 1, $\varnothing \varnothing \bigcirc \bigcirc$

\section{Pregnancy and Postpartum}

\section{Women Planning Pregnancy}

The choice of therapy depends on the patient's preference, disease history, the presence of high TSH-R-Ab levels, and the timescale for conception [134-138]. Pregnancy should be postponed if hyperthyroidism is inadequately controlled until euthyroidism is reached and confirmed on two occasions over 2 months on a stable therapeutic regimen. Patients should be informed about: (1) the increased risk of ATD-associated birth defects; (2) the possibility of stopping ATD during gestational weeks 6-10; (3) the preference for PTU, when ATD are necessary before/during the first trimester of pregnancy; (4) the advice to switch from PTU to MMI after 16 weeks of pregnancy; and (5) not to use block-replacement therapy. Pregnancy should be delayed for 6 months post-RAI, and contraception is advised during that period. Thyroidectomy is indicated in the case of contraindications/rejection of ATD/RAI. After surgery, euthyroidism should be confirmed prior to conception.

\section{Recommendations}

33 Women with GD of reproductive age should be offered preconception counseling and be stably euthyroid before attempting pregnancy. $1, \varnothing \varnothing \bigcirc \bigcirc$
34 Women with GD should be instructed to immediately confirm pregnancy and contact their physician. 1, $\varnothing \varnothing \varnothing \varnothing$

35 Women treated with MMI should be switched to PTU when planning pregnancy and/or during the first trimester of pregnancy. $1, \varnothing \varnothing \varnothing \varnothing$

\section{Pregnant Women and GD}

The initial ATD daily dose depends on the severity of hyperthyroidism: MMI 5-15 mg, CBZ 10-30 mg, PTU 50-200 mg [139, 140]. MMI (CBZ) embryopathy, including dysmorphic facies, aplasia cutis, choanal or esophageal atresia, abdominal wall defects, umbilicocele, and ventricular septal defects, affects $2-4 \%$ of children who have been exposed to MMI, especially during gestational weeks $6-10[137,141]$. The prevalence of birth defects is the same with PTU, but the spectrum of defects is less severe, primarily consisting of face and neck cysts and urinary tract abnormalities in males [142]. Propranolol 10$40 \mathrm{mg}$, 3-4 times daily may be used; however, long-term treatment should be avoided since beta-blockers may cause intrauterine growth restriction, fetal bradycardia, and neonatal hypoglycemia [143]. Thyroidectomy may be indicated in the case of allergy/contraindications to ATD and should be performed in the second trimester of pregnancy $[136,144]$.

Only $5 \%$ of TSH-R-Ab-negative patients relapse within 8 weeks after ATD withdrawal [145]. Therefore, when pregnancy is determined and remission is probable, ATD can be withdrawn and thyroid function monitored every 2 weeks during the first trimester of pregnancy. If the pregnant woman remains euthyroid, thyroid function is monitored every 4 weeks during the second/third trimester. A treatment period of less than 6 months, a high daily ATD dose, high levels of TSH-R-Ab, low/suppressed serum TSH levels while on medication, and the presence of GO increased the recurrence risk after ATD withdrawal $[146,147]$. Maternal FT4 (or TT4) values should be maintained at the upper limit of the pregnancy-specific thyroid function tests [148]. During the third trimester, discontinuation of ATD is often feasible due to the disappearance of maternal TSH-R-Ab $[135,136]$. In contrast, monitoring for the onset of neonatal dysthyroidism is indicated in the presence of high TSH-R-Ab serum levels ( $>3$ times the cut-off) in the mother in late pregnancy [149-151]. In line with this and as a strong recommendation, all patients with a history of autoimmune thyroid disease should have their TSH-R-Ab serum levels measured at the first presentation of pregnancy using either a sensitive binding or a functional cell-based bioassay, and, 
if they are elevated, again at 18-22 weeks of gestation [5, 21-23, 43, 44, 149, 150]. Finally, fetal/neonatal hyperthyroidism requires an acute management, including MMI, beta-blockade, and cardiovascular support therapy [43].

Recommendations

36 All patients with a history of autoimmune thyroid disease should have their TSH-R-Ab serum levels measured at the first presentation of pregnancy using either a sensitive binding or a functional cell-based bioassay and, if they are elevated, again at 18-22 weeks of gestation. $1, \varnothing \varnothing \varnothing \varnothing$

37 If the maternal TSH-R-Ab concentration remains high ( $>3$ times the cut-off), monitoring of the fetus for thyroid dysfunction throughout pregnancy is recommended. $1, \varnothing \varnothing \varnothing \varnothing$

38 During pregnancy the lowest possible dose of ATD should be given and the block-and-replace ATD regimen is discouraged. $1, \varnothing \varnothing \varnothing \varnothing$

39 Maternal FT4 (TT4) and TSH should be measured every 2 weeks after the initiation of therapy, and every 4 weeks after achieving the target value. $1, \varnothing \varnothing \bigcirc \bigcirc$

40 A change from PTU to MMI should be considered if ATD are required after 16 weeks gestation. $1, \varnothing 0 \bigcirc \bigcirc$

$41 \mathrm{In}$ women on a low dose of MMI ( $<5-10 \mathrm{mg}$ /day) or PTU ( $<50-100 \mathrm{mg} /$ day), ATD may be stopped during gestation prior to weeks 6-10.2, Ø૦००

\section{Postpartum Phase}

The risk of GD recurrence was highest 7-9 months postpartum (RR 3.8) in studies conducted in Denmark and Japan $[135,152]$. Only small amounts of ATD enter into breast milk, and low doses of PTU $(<250 \mathrm{mg})$ and MMI ( $<20 \mathrm{mg}$ ) are considered safe for the mother and child. ATD should be taken after having breastfed the child and in divided doses $[153,154]$.

\section{Recommendations}

42 Lactating women with GD should be offered the same treatments as non-lactating women. $1, \varnothing \varnothing \bigcirc \bigcirc$

$43 \mathrm{MMI}$ is recommended during lactation, given the concerns about PTU-mediated hepatotoxicity. $1, \varnothing \varnothing \bigcirc \bigcirc$

\section{The Elderly, Children and Adolescents, and Immune Reconstitution}

\section{Elderly}

Although the incidence of GD decreases with advancing age, cases may still occur in patients in their 8th and 9th decades of life. A typical presentation with weight loss, tremor, agitation, and heat intolerance can occur; however, older individuals sometimes present with subtle symptoms such as fatigue, mood disturbance, or breathlessness (termed "apathetic thyrotoxicosis"). Dramatic presentations with atrial fibrillation, congestive cardiac failure, or ischemic acute coronary syndrome are also more frequent in older people. Treatment for those with severe thyrotoxicosis should be along similar lines to that in younger people, with an initial course of ATD to render the patient euthyroid, along with beta-blockers if appropriate. If there is atrial fibrillation or other tachyarrhythmia or cardiac compromise, it is good practice to proceed to early definitive therapy, normally with RAI, to prevent any further heart complication from recurrent hyperthyroidism. In older or frail patients with milder hyperthyroidism and without cardiac compromise, long-term low-dose MMI (CBZ) 2.5-5 mg daily is an effective and well-tolerated treatment, especially when there is no access to RAI and/or contraindication to thyroidectomy. Older patients are more likely to suffer severe consequences from ATD-induced agranulocytosis [155], and it is important to be meticulous in warning people about this issue, and providing written information to family or caregivers in the case of cognitive impairment. In addition, older patients have a higher chance of developing GO [156], so should be carefully assessed for this: where relevant, smoking cessation advice should be given and treatment-related hypothyroidism should be assiduously avoided.

\section{Recommendations}

44 Older patients who have had atrial fibrillation, cardiac failure, or cardiac ischemic symptoms precipitated by hyperthyroidism should undergo definitive therapy, usually RAI. $1, \varnothing \varnothing \varnothing \bigcirc$

45 Long-term MMI (CBZ) should be considered as a satisfactory treatment for older individuals with mild GD. 2, $\varnothing 000$

\section{Childhood and Adolescence}

Children and teenagers frequently present late with GD and in retrospect features such as impaired educational performance, change in behavior, anxiety, or sleep disturbance may have been present for years before the cause is recognized. Importantly, the diagnosis is easily overlooked in teenage girls with weight loss who are assumed to have an eating disorder. The outcome of ATD treatment of younger people with GD is disappointing, as compared to the results in adults. Remission rates fol- 
lowing 2 or more years of ATD therapy do not exceed $25 \%[157,158]$, and this necessitates longer-term ATD administration in most children. Furthermore, there is a higher prevalence of adverse reactions to ATD in children and this means that PTU is no longer recommended for use in childhood, owing to hepatic failure in up to 1 in 2,000 children exposed [159]. If children develop adverse reactions while taking ATD, early surgery with total thyroidectomy is generally recommended. Over recent years, more confidence has been gained about the safety of RAI, particularly in postpubertal younger people [160]. Thus, long-term low-dose MMI (CBZ) followed, if necessary, by surgery or RAI when the child reaches a suitable age (16 years or older) is frequently the sequence of therapy in this age group. Any episode of hyperthyroidism or hypothyroidism (as a consequence of treatment), will likely have an effect on educational progress, and this factor should be taken into account in all decision making.

Recommendations

46 PTU should be avoided in children and adolescents. 1 , $\varnothing \varnothing \varnothing \varnothing$

47 Long-term MMI (CBZ) should be the mainstay of treatment in children with GD. $1, \varnothing \varnothing \varnothing \bigcirc$

48 Thyroidectomy is the primary definitive therapy in childhood, but in postpubertal children RAI can be

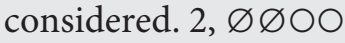

\section{Immune Reconstitution}

The first demonstration of immune reconstitution GD was in multiple sclerosis patients who had received lymphocyte-depleting alemtuzumab (Campath-H1) antibody treatment [161]. This treatment causes initial lymphopenia, but $12-24$ months later $20-30 \%$ of patients developed TSH-R-Ab-positive GD, as lymphocyte populations recover. A similar pattern of GD has been observed in patients with HIV who have received effective highly active antiretroviral therapy, with hyperthyroidism developing as CD4 lymphocyte counts increase [162]. Immune reconstitution GD has also been observed in bone marrow transplant patients. In most cases, the hyperthyroidism is manageable and, depending on the underlying condition, it is not an indication to discontinue the immunomodulatory therapy that precipitated it. Although initial reports suggested that definitive therapy was warranted in these patients, additional experience now suggests that they can be managed similarly to patients with "spontaneous" GD [163]. However, as the immunological "insult" may be transient in these cases, a reasonable approach is to treat with ATD until circulating TSH-R-Ab become undetectable.

Recommendations

49 Graves' hyperthyroidism precipitated by an immunomodulatory therapy is not a mandatory indication to stop that precipitating treatment, nor is it a mandatory indication for definitive therapy for hyperthyroidism. $1, \varnothing \bigcirc \bigcirc \bigcirc$

50 Sequential monitoring of serum TSH-R-Ab levels can be used to guide the duration of ATD therapy in patients with immune reconstitution GD. 2, Ø૦०০

\section{Perspectives and Conclusions}

Ongoing preclinical and clinical trials are assessing the effectiveness of novel drugs and/or substances that could modify the natural history of GD by modulating its pathogenesis. These therapeutic agents include TSH-R monoclonal Abs [164], immunomodulatory TSH-R peptides, and small-molecule TSH-R ligands [165] that can block the thyroid-stimulating effect of TSH-R-Ab, thus acting as TSH-R-Ab antagonists. However, the data are still too preliminary to predict whether these compounds will become available for the daily management of GD patients. Likewise, the use of biologicals, such as rituximab, although based on a sound rationale, is not supported by sufficient evidence [166]. Currently the optimal management depends on patient preference and specific patient clinical features such as age, history of arrhythmia or ischemic heart disease, size of goiter, and severity of thyrotoxicosis. Since each of the treatment modalities has unique limitations and adverse consequences, physicians need to be familiar with the advantages and disadvantages of each therapy in order to best counsel their patients.

The target audience for this guideline are physicians providing care for patients with GD. In this document rational medical practice is outlined. This guideline does not replace clinical judgment, individual decision making, or the wishes of the patient or family. Rather, each recommendation should be evaluated in light of these elements in order that optimal patient care is delivered. When the level of care required is best provided in centers where there is specific expertise, referral to such centers should be considered. The 50 recommendations that form these guidelines are presented together in Table 6 . 
Table 6. 50 recommendations that form these guidelines

\begin{tabular}{|c|c|c|}
\hline Number & Recommendation & $\begin{array}{l}\text { Strength and } \\
\text { level of } \\
\text { evidence }\end{array}$ \\
\hline 1 & $\begin{array}{l}\text { The measurement of TSH-R-Ab is a sensitive and specific tool for rapid and accurate diagnosis and differential diagnosis of } \\
\text { Graves' hyperthyroidism }\end{array}$ & $1, \varnothing \varnothing \varnothing \varnothing$ \\
\hline 2 & $\begin{array}{l}\text { When technically available, differentiation of TSH-R-Ab functionality is helpful and predictive in Graves' patients during } \\
\text { pregnancy/post-partum, as well as for extra-thyroidal manifestations }\end{array}$ & 2, ØØØం \\
\hline 3 & $\begin{array}{l}\text { US examination, comprising conventional grey scale analysis and color-flow or power Doppler examination is recommended as } \\
\text { the imaging procedure to support the diagnosis of Graves' hyperthyroidism }\end{array}$ & $1, \varnothing \varnothing \varnothing \varnothing$ \\
\hline 4 & $\begin{array}{l}\text { Scintigraphy of the thyroid is suggested when thyroid nodularity coexists with hyperthyroidism, and prior to radioactive iodine } \\
\text { therapy }\end{array}$ & 2, ØØØం \\
\hline 5 & $\begin{array}{l}\text { Patients with newly diagnosed Graves' hyperthyroidism should be treated with ATD. RAI therapy or thyroidectomy may be } \\
\text { considered in patients who prefer this approach }\end{array}$ & 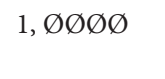 \\
\hline 6 & MMI (CBZ) should be used in every non-pregnant patient who chooses ATD therapy for Graves' hyperthyroidism & $1, \varnothing \varnothing \varnothing \varnothing$ \\
\hline 7 & MMI is administered for $12-18$ months then discontinued if the TSH and TSH-R-Ab levels are normal & 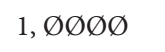 \\
\hline 8 & $\begin{array}{l}\text { Measurement of TSH-R-Ab levels prior to stopping ATD therapy is recommended, as it aids in predicting which patients can be } \\
\text { weaned from the medication, with normal levels indicating a greater chance of remission }\end{array}$ & $1, \varnothing \varnothing \varnothing \varnothing$ \\
\hline 9 & $\begin{array}{l}\text { Patients with persistently high TSH-R-Ab at } 12-18 \text { months can continue MMI therapy, repeating the TSH-R-Ab measurement } \\
\text { an after additional } 12 \text { months, or opt for RAI or thyroidectomy }\end{array}$ & $1, \varnothing \varnothing \varnothing 0$ \\
\hline 10 & $\begin{array}{l}\text { Patients should be informed of potential side effects of ATD and the necessity of informing the physician promptly if they } \\
\text { should develop jaundice, light-colored stools, dark urine, fever, pharyngitis, or cystitis }\end{array}$ & $1, \varnothing \varnothing 00$ \\
\hline 11 & $\begin{array}{l}\text { In patients taking ATD, a differential white blood cell count should be obtained during febrile illness and/or pharyngitis, and } \\
\text { liver function should be assessed in those who experience jaundice, light-colored stools, or dark urine }\end{array}$ & $1, \varnothing \varnothing 00$ \\
\hline 12 & Beta-adrenergic blockade is recommended in all suitable patients with Graves' hyperthyroidism & $1, \varnothing \varnothing \varnothing \varnothing$ \\
\hline 13 & $\begin{array}{l}\text { If a patient with GD becomes hyperthyroid after completing a first course of ATD, definitive treatment with RAI or } \\
\text { thyroidectomy is recommended. Continued long-term low-dose MMI can be considered in patients not in remission who } \\
\text { prefer this approach }\end{array}$ & $1, \varnothing \varnothing \varnothing 0$ \\
\hline 14 & Treatment of SH is recommended in Graves' patients $>65$ years with serum TSH levels that are persistently $<0.1 \mathrm{mIU} / \mathrm{L}$ & $1, \varnothing \varnothing 00$ \\
\hline 15 & ATD should be the first choice of treatment of Graves' SH & $1, \varnothing \varnothing ం 0$ \\
\hline 16 & $\begin{array}{l}\text { A multimodality treatment approach to GD patients with thyroid storm should be used, including ATD therapy, glucocorticoid } \\
\text { administration, beta-adrenergic blockade, cooling blankets, volume resuscitation, nutritional support, respiratory care, and } \\
\text { monitoring in an intensive care unit }\end{array}$ & $1, \varnothing \varnothing 00$ \\
\hline 17 & $\begin{array}{l}\text { There are no absolute indications for RAI therapy, but it is often recommended for patients with side-effects to, or recurrence } \\
\text { after a course of ATD }\end{array}$ & $1, \varnothing \varnothing ం О$ \\
\hline 18 & Verbal as well as written information on all aspects of efficacy and potential side-effects of RAI therapy should be provided & $1, \varnothing \varnothing ం 0$ \\
\hline 19 & $\begin{array}{l}\text { If ATD are used before RAI therapy they should be paused around } 1 \text { week before and after therapy in order not to decrease the } \\
\text { efficacy of RAI }\end{array}$ & $1, \varnothing \varnothing \varnothing \varnothing$ \\
\hline 20 & No dose calculation can secure long-term euthyroidism and it is fully acceptable to offer a fixed dose of RAI & $1, \varnothing \varnothing \varnothing ం$ \\
\hline 21 & Pregnancy and breast feeding constitute absolute contraindications to RAI therapy & 1, ØØØ० \\
\hline 22 & Conception should be postponed until at least 6 months after RAI in both males and females & $1, \varnothing \varnothing \varnothing 0$ \\
\hline 23 & If used in children, ablative doses aiming at rapid hypothyroidism should be administered & $1, \varnothing \varnothing 00$ \\
\hline 24 & $\begin{array}{l}\text { If surgery is selected, total thyroidectomy is the procedure of choice, and should be performed by a skilled surgeon with high } \\
\text { annual volumes of thyroidectomies }\end{array}$ & $1, \varnothing \varnothing \varnothing \varnothing$ \\
\hline 25 & Euthyroidism should be restored by ATD prior to surgery to avoid peri- or postoperative exacerbation of thyrotoxicosis & $1, \varnothing \varnothing \varnothing \varnothing$ \\
\hline 26 & Vitamin D deficiency should be corrected to reduce the postoperative risk of hypocalcemia & $1, \varnothing \varnothing \varnothing \varnothing$ \\
\hline
\end{tabular}


Table 6 (continued)

\begin{tabular}{|c|c|c|}
\hline Number & Recommendation & $\begin{array}{l}\text { Strength and } \\
\text { level of } \\
\text { evidence }\end{array}$ \\
\hline 28 & In patients with GO, hyperthyroidism should be promptly controlled by ATD, and euthyroidism stably maintained & $1, \varnothing \varnothing \varnothing \varnothing$ \\
\hline 29 & $\begin{array}{l}\text { Patients treated with RAI should receive steroid prophylaxis if mild and active GO preexists or there are risk factors for RAI- } \\
\text { associated GO occurrence or progression }\end{array}$ & 1, ØØØØ \\
\hline 30 & $\begin{array}{l}\text { In patients with moderate-to-severe and active GO, treatment of GO should be the priority. Euthyroidism should be promptly } \\
\text { restored with ATD and stably maintained }\end{array}$ & 1, ØØØØ \\
\hline 31 & Patients with sight-threatening GO should be treated with ATD & $1, \varnothing \varnothing 00$ \\
\hline 32 & Treatment for hyperthyroidism in patients with inactive GO can be selected independently of GO & $1, \varnothing \varnothing 00$ \\
\hline 33 & $\begin{array}{l}\text { Women with GD of reproductive age should be offered preconception counseling and be stably euthyroid before attempting } \\
\text { pregnancy }\end{array}$ & $1, \varnothing \varnothing 00$ \\
\hline 36 & $\begin{array}{l}\text { All patients with a history of autoimmune thyroid disease should have their TSH-R-Ab serum levels measured at the first } \\
\text { presentation of pregnancy using either a sensitive binding or a functional cell-based bioassay and, if they are elevated, again at } \\
18-22 \text { weeks of gestation }\end{array}$ & $1, \varnothing \varnothing \varnothing \varnothing$ \\
\hline 37 & $\begin{array}{l}\text { If the maternal TSH-R-Ab concentration remains high ( }>3 \text { times the cut-off), monitoring of the fetus for thyroid dysfunction } \\
\text { throughout pregnancy is recommended }\end{array}$ & 1, ØØØØ \\
\hline 38 & During pregnancy the lowest possible dose of ATD should be given and the block-and-replace ATD regimen is discouraged & $1, \varnothing \varnothing \varnothing \varnothing$ \\
\hline 39 & $\begin{array}{l}\text { Maternal FT4 (TT4) and TSH should be measured every } 2 \text { weeks after initiation of therapy, and every } 4 \text { weeks after achieving } \\
\text { the target value }\end{array}$ & $1, \varnothing \varnothing 00$ \\
\hline 40 & A change from PTU to MMI should be considered if ATD are required after 16 weeks gestation & $1, \varnothing 000$ \\
\hline 45 & Long-term MMI (CBZ) should be considered as a satisfactory treatment for older individuals with mild GD & 2, Øం०O \\
\hline 46 & PTU should be avoided in children and adolescents & $1, \varnothing \varnothing \varnothing \varnothing$ \\
\hline 47 & Long-term MMI (CBZ) should be the mainstay of treatment in children with GD & $1, \varnothing \varnothing \varnothing 0$ \\
\hline 48 & Thyroidectomy is the primary definitive therapy in childhood, but in post-pubertal children RAI can be considered & $2, \varnothing \varnothing 00$ \\
\hline 49 & $\begin{array}{l}\text { Graves' hyperthyroidism precipitated by an immunomodulatory therapy is not a mandatory indication to stop that precipitating } \\
\text { treatment, nor is it a mandatory indication for definitive therapy for hyperthyroidism }\end{array}$ & $1, \varnothing 000$ \\
\hline 50 & $\begin{array}{l}\text { Sequential monitoring of serum TSH-R-Ab levels can be used to guide the duration of ATD therapy in patients with immune } \\
\text { reconstitution GD }\end{array}$ & $2, \varnothing 000$ \\
\hline
\end{tabular}




\section{Acknowledgments}

The authors are grateful to Miss Ute Gitzen and Miss Tanja Diana, MSc, PhD, Thyroid Research Lab, JGU Medical Center, Mainz, Germany, for their valuable help in coediting the manuscript and compiling the reference list using Endnote software.

\section{Disclosure Statement}

L.B., L.H., L.L., and K.P. have nothing to disclose; S.H.P. consults for Apitope, and G.J.K. consults for Apitope and Quidel.

\section{References}

1 Bahn RS, Burch HB, Cooper DS, Garber JR, Greenlee MC, Klein I, Laurberg P, McDougall IR, Montori VM, Rivkees SA, Ross DS, Sosa JA, Stan MN; American Thyroid Association; American Association of Clinical Endocrinologists: Hyperthyroidism and other causes of thyrotoxicosis: management guidelines of the American Thyroid Association and American Association of Clinical Endocrinologists. Endocr Pract 2011;17:456-520.

2 Bartalena L: Diagnosis and management of Graves disease: a global overview. Nat Rev Endocrinol 2013;9:724-734.

3 Kahaly GJ, Dillmann WH: Thyroid hormone action in the heart. Endocr Rev 2005;26:704728.

4 Biondi B, Kahaly GJ: Cardiovascular involvement in patients with different causes of hyperthyroidism. Nat Rev Endocrinol 2010;6: 431-443.

5 Ross DS, Burch HB, Cooper DS, Greenlee MC, Laurberg P, Maia AL, Rivkees SA, Samuels M, Sosa JA, Stan MN, Walter MA: 2016 American Thyroid Association guidelines for diagnosis and management of hyperthyroidism and other causes of thyrotoxicosis. Thyroid 2016;26:1343-1421.

6 Smith TJ, Hegedus L: Graves' disease. N Engl J Med 2016;375:1552-1565.

7 Nystrom HF, Jansson S, Berg G: Incidence rate and clinical features of hyperthyroidism in a long-term iodine sufficient area of Sweden (Gothenburg) 2003-2005. Clin Endocrinol 2013;78:768-776.

8 McLeod DS, Caturegli P, Cooper DS, Matos PG, Hutfless S: Variation in rates of autoimmune thyroid disease by race/ethnicity in US military personnel. JAMA 2014;311:15631565.

9 Rapoport B, Chazenbalk GD, Jaume JC, McLachlan SM: The thyrotropin (TSH) receptor: interaction with TSH and autoantibodies. Endocr Rev 1998;19:673-716.

10 Rapoport B, McLachlan SM: TSH receptor cleavage into subunits and shedding of the Asubunit; a molecular and clinical perspective. Endocr Rev 2016;37:114-134.

11 Smith TJ, Hegedus L, Douglas RS: Role of insulin-like growth factor-1 (IGF-1) pathway in the pathogenesis of Graves' orbitopathy. Best Pract Res Clin Endocrinol Metab 2012;26: 291-302.
12 Brix TH, Kyvik KO, Christensen K, Hegedus $\mathrm{L}$ : Evidence for a major role of heredity in Graves' disease: a population-based study of two Danish twin cohorts. J Clin Endocrinol Metab 2001;86:930-934.

13 Inaba H, De Groot LJ, Akamizu T: Thyrotropin receptor epitope and human leukocyte antigen in Graves' disease. Front Endocrinol 2016;7:120.

14 Lee HJ, Li CW, Hammerstad SS, Stefan M, Tomer Y: Immunogenetics of autoimmune thyroid diseases: a comprehensive review. J Autoimmun 2015;64:82-90.

15 Strieder TG, Prummel MF, Tijssen JG, Endert E, Wiersinga WM: Risk factors for and prevalence of thyroid disorders in a cross-sectional study among healthy female relatives of patients with autoimmune thyroid disease. Clin Endocrinol 2003;59:396-401.

16 Laurberg P, Pedersen KM, Vestergaard $\mathrm{H}$, Sigurdsson G: High incidence of multinodular toxic goitre in the elderly population in a low iodine intake area vs. high incidence of Graves' disease in the young in a high iodine intake area: comparative surveys of thyrotoxicosis epidemiology in East-Jutland Denmark and Iceland. J Intern Med 1991;229:415-420.

17 Brix TH, Hansen PS, Kyvik KO, Hegedus L: Cigarette smoking and risk of clinically overt thyroid disease: a population-based twin case-control study. Arch Intern Med 2000; 160:661-666.

18 Swiglo BA, Murad MH, Schunemann HJ, Kunz R, Vigersky RA, Guyatt GH, Montori VM: A case for clarity, consistency, and helpfulness: state-of-the-art clinical practice guidelines in endocrinology using the grading of recommendations, assessment, development, and evaluation system. J Clin Endocrinol Metab 2008;93:666-673.

19 de los Santos ET, Starich GH, Mazzaferri EL: Sensitivity, specificity, and cost-effectiveness of the sensitive thyrotropin assay in the diagnosis of thyroid disease in ambulatory patients. Arch Intern Med 1989;149:526-532.

20 Spencer CA, LoPresti JS, Patel A, Guttler RB, Eigen A, Shen D, Gray D, Nicoloff JT: Applications of a new chemiluminometric thyrotropin assay to subnormal measurement. J Clin Endocrinol Metab 1990;70:453-460.

21 Grebe SK, Kahaly GJ: Laboratory testing in hyperthyroidism. Am J Med 2012;125:S2.
22 Bartalena L, Burch HB, Burman KD, Kahaly GJ: A 2013 European survey of clinical practice patterns in the management of Graves' disease. Clin Endocrinol 2016;84:115-120.

23 Kahaly GJ, Olivo PD: Graves' disease. N Engl J Med 2017;376:184.

24 Kahaly GJ, Diana T: TSH receptor antibody functionality and nomenclature. Front Endocrinol 2017;8:28.

25 Tozzoli R, Bagnasco M, Giavarina D, Bizzaro $\mathrm{N}$ : TSH receptor autoantibody immunoassay in patients with Graves' disease: improvement of diagnostic accuracy over different generations of methods: systematic review and meta-analysis. Autoimmun Rev 2012;12: 107-113.

26 Kahaly GJ: Bioassays for TSH receptor antibodies: quo vadis? Eur Thyroid J 2015;4:3-5.

27 Araki N, Iida M, Amino N, Morita S, Ide A, Nishihara E, Ito M, Saito J, Nishikawa T, Katsuragi K, Miyauchi A: Rapid bioassay for detection of thyroid-stimulating antibodies using cyclic adenosine monophosphate-gated calcium channel and aequorin. Eur Thyroid J 2015;4:14-19.

28 Lytton SD, Kahaly GJ: Bioassays for TSH-receptor autoantibodies: an update. Autoimmun Rev 2010;10:116-122.

29 Lytton SD, Li Y, Olivo PD, Kohn LD, Kahaly GJ: Novel chimeric thyroid-stimulating hormone-receptor bioassay for thyroid-stimulating immunoglobulins. Clin Exp Immunol 2010;162:438-446.

30 Li Y, Kim J, Diana T, Klasen R, Olivo PD, Kahaly GJ: A novel bioassay for anti-thyrotrophin receptor autoantibodies detects both thyroid-blocking and stimulating activity. Clin Exp Immunol 2013;173:390-397.

31 Diana T, Kanitz M, Lehmann M, Li Y, Olivo PD, Kahaly GJ: Standardization of a bioassay for thyrotropin receptor stimulating autoantibodies. Thyroid 2015;25:169-175.

32 Diana T, Li Y, Olivo PD, Lackner KJ, Kim H, Kanitz M, Kahaly GJ: Analytical performance and validation of a bioassay for thyroidblocking antibodies. Thyroid 2016;26:734740 .

33 Diana T, Krause J, Olivo PD, Konig J, Kanitz M, Decallonne B, Kahaly GJ: Prevalence and clinical relevance of thyroid stimulating hormone receptor-blocking antibodies in autoimmune thyroid disease. Clin Exp Immunol 2017;189:304-309. 
34 Diana T, Wuster C, Kanitz M, Kahaly GJ: Highly variable sensitivity of five binding and two bio-assays for TSH-receptor antibodies. J Endocrinol Invest 2016;39:1159-1165.

35 Diana T, Wüster C, Olivo PD, Unterrainer A, König J, Kanitz M, Bossowski A, Decallonne B, Kahaly GJ: Performance and specificity of six immunoassays for TSH receptor antibodies: a multicenter study. Eur Thyroid J 2017;6:2.

36 Lytton SD, Ponto KA, Kanitz M, Matheis N, Kohn LD, Kahaly GJ: A novel thyroid stimulating immunoglobulin bioassay is a functional indicator of activity and severity of Graves' orbitopathy. J Clin Endocrinol Metab 2010;95:2123-2131.

37 Ponto KA, Kanitz M, Olivo PD, Pitz S, Pfeiffer N, Kahaly GJ: Clinical relevance of thyroidstimulating immunoglobulins in graves' ophthalmopathy. Ophthalmology 2011;118: 2279-2285.

38 Ponto KA, Diana T, Binder H, Matheis N, Pitz S, Pfeiffer N, Kahaly GJ: Thyroid-stimulating immunoglobulins indicate the onset of dysthyroid optic neuropathy. J Endocrinol Invest 2015;38:769-777.

39 Kahaly GJ, Diana T, Glang J, Kanitz M, Pitz S, Konig J: Thyroid stimulating antibodies are highly prevalent in Hashimoto's thyroiditis and associated orbitopathy. J Clin Endocrinol Metab 2016;101:1998-2004.

40 Diana T, Brown RS, Bossowski A, Segni M, Niedziela M, Konig J, Bossowska A, Ziora K, Hale A, Smith J, Pitz S, Kanitz M, Kahaly GJ: Clinical relevance of thyroid-stimulating autoantibodies in pediatric graves' disease - a multicenter study. J Clin Endocrinol Metab 2014;99:1648-1655.

41 Kampmann E, Diana T, Kanitz M, Hoppe D, Kahaly GJ: Thyroid stimulating but not blocking autoantibodies are highly prevalent in severe and active thyroid-associated orbitopathy: a prospective study. Int J Endocrinol 2015;2015:678194.

42 Stozek K, Bossowski A, Ziora K, Bossowska A, Mrugacz M, Noczynska A, Walczak M, Petriczko E, Pyrzak B, Kucharska A, Szalecki M, Diana T, Kahaly GJ: Functional TSH receptor antibodies in children with autoimmune thyroid diseases. Autoimmunity 2018;51:62-68.

43 Kiefer FW, Klebermass-Schrehof K, Steiner M, Worda C, Kasprian G, Diana T, Kahaly GJ, Gessl A: Fetal/neonatal thyrotoxicosis in a newborn from a hypothyroid woman with Hashimoto thyroiditis. J Clin Endocrinol Metab 2017;102:6-9.

44 Mestman JH: Fetal hyperthyroidism resulted from TSI in a mother with Hashimoto's hypothyroidism. Clin Thyroidol 2017;29:32-34.

45 McKee A, Peyerl F: TSI assay utilization: impact on costs of Graves' hyperthyroidism diagnosis. Am J Manag Care 2012;18:e1-14.

46 Goichot B, Bouee S, Castello-Bridoux C, Caron P: Survey of clinical practice patterns in the management of 992 hyperthyroid patients in France. Eur Thyroid J 2017;6:152-159.
47 Kahaly GJ, Bartalena L, Hegedus L: The American Thyroid Association/American Association of Clinical Endocrinologists guidelines for hyperthyroidism and other causes of thyrotoxicosis: a European perspective. Thyroid 2011;21:585-591.

48 Hegedus L: Thyroid ultrasound. Endocrinol Metab Clin North Am 2001;30:339-360.

49 Vitti P, Rago T, Mancusi F, Pallini S, Tonacchera M, Santini F, Chiovato L, Marcocci C, Pinchera A: Thyroid hypoechogenic pattern at ultrasonography as a tool for predicting recurrence of hyperthyroidism after medical treatment in patients with Graves' disease. Acta Endocrinol 1992;126:128-131.

50 Erdogan MF, Anil C, Cesur M, Baskal N, Erdogan G: Color flow Doppler sonography for the etiologic diagnosis of hyperthyroidism. Thyroid 2007;17:223-228.

51 Ralls PW, Mayekawa DS, Lee KP, Colletti PM, Radin DR, Boswell WD, Halls JM: Color-flow Doppler sonography in Graves disease: "thyroid inferno." AJR Am J Roentgenol 1988; 150:781-784.

$52 \mathrm{Kim}$ TK, Lee EJ: The value of the mean peak systolic velocity of the superior thyroidal artery in the differential diagnosis of thyrotoxicosis. Ultrasonography 2015;34:292-296.

53 Emiliano AB, Governale L, Parks M, Cooper DS: Shifts in propylthiouracil and methimazole prescribing practices: antithyroid drug use in the United States from 1991 to 2008. J Clin Endocrinol Metab 2010;95:2227-2233.

54 Brito JP, Schilz S, Singh Ospina N, RodriguezGutierrez R, Maraka S, Sangaralingham LR, Montori VM: Antithyroid drugs - the most common treatment for Graves' disease in the United States: a nationwide population-based study. Thyroid 2016;26:1144-1145.

55 Cooper DS: Antithyroid drugs in the management of patients with Graves' disease: an evidence-based approach to therapeutic controversies. J Clin Endocrinol Metab 2003;88: 3474-3481.

56 Cooper DS: Antithyroid drugs. N Engl J Med 2005;352:905-917.

57 Abraham P, Avenell A, McGeoch SC, Clark LF, Bevan JS: Antithyroid drug regimen for treating Graves' hyperthyroidism. Cochrane Database Syst Rev 2010:CD003420.

58 Leschik JJ, Diana T, Olivo PD, Konig J, Krahn U, Li Y, Kanitz M, Kahaly GJ: Analytical performance and clinical utility of a bioassay for thyroid-stimulating immunoglobulins. Am J Clin Pathol 2013;139:192-200.

59 Giuliani C, Cerrone D, Harii N, Thornton M, Kohn LD, Dagia NM, Bucci I, Carpentieri M, Di Nenno B, Di Blasio A, Vitti P, Monaco F, Napolitano G: A TSHR-LH/CGR chimera that measures functional thyroid-stimulating autoantibodies (TSAb) can predict remission or recurrence in Graves' patients undergoing antithyroid drug (ATD) treatment. J Clin Endocrinol Metab 2012;97:E1080-E1087.
60 Laurberg P, Berman DC, Andersen S, Bulow Pedersen I: Sustained control of Graves' hyperthyroidism during long-term low-dose antithyroid drug therapy of patients with severe Graves' orbitopathy. Thyroid 2011;21: 951-956.

61 Elbers L, Mourits M, Wiersinga W: Outcome of very long-term treatment with antithyroid drugs in Graves' hyperthyroidism associated with Graves' orbitopathy. Thyroid 2011;21: 279-283.

62 Leger J, Carel JC: Management of endocrine disease: arguments for the prolonged use of antithyroid drugs in children with Graves' disease. Eur J Endocrinol 2017;177:R59-R67.

63 Pearce SH: Spontaneous reporting of adverse reactions to carbimazole and propylthiouracil in the UK. Clin Endocrinol 2004;61:589-594.

64 Yang J, Zhu YJ, Zhong JJ, Zhang J, Weng WW, Liu ZF, Xu Q, Dong MJ: Characteristics of antithyroid drug-induced agranulocytosis in patients with hyperthyroidism: a retrospective analysis of 114 cases in a single institution in China involving 9690 patients referred for radioiodine treatment over 15 years. Thyroid 2016;26:627-633.

65 Nakamura H, Miyauchi A, Miyawaki N, Imagawa J: Analysis of 754 cases of antithyroid drug-induced agranulocytosis over 30 years in Japan. J Clin Endocrinol Metab 2013; 98:4776-4783.

66 Watanabe N, Narimatsu H, Noh JY, Yamaguchi T, Kobayashi K, Kami M, Kunii Y, Mukasa K, Ito K, Ito K: Antithyroid drug-induced hematopoietic damage: a retrospective cohort study of agranulocytosis and pancytopenia involving 50,385 patients with Graves' disease. J Clin Endocrinol Metab 2012; 97:E49-E53.

67 Chen PL, Shih SR, Wang PW, Lin YC, Chu CC, Lin JH, Chen SC, Chang CC, Huang TS, Tsai KS, Tseng FY, Wang CY, Lu JY, Chiu WY, Chang CC, Chen YH, Chen YT, Fann CS, Yang WS, Chang TC: Genetic determinants of antithyroid drug-induced agranulocytosis by human leukocyte antigen genotyping and genome-wide association study. Nat Commun 2015;6:7633.

68 Hallberg P, Eriksson N, Ibanez L, BondonGuitton E, Kreutz R, Carvajal A, Lucena MI, Ponce ES, Molokhia M, Martin J, Axelsson T, Yue QY, Magnusson PK, Wadelius M; EuDACc: Genetic variants associated with antithyroid drug-induced agranulocytosis: a genome-wide association study in a European population. Lancet Diabetes Endocrinol 2016;4:507-516.

69 Plantinga TS, Arts P, Knarren GH, Mulder AH, Wakelkamp IM, Hermus AR, Joosten LA, Netea MG, Bisschop PH, de Herder WW, Beijers HJ, de Bruin IJ, Gilissen C, Veltman JA, Hoischen A, Smit JW, Netea-Maier RT: Rare NOX3 variants confer susceptibility to agranulocytosis during thyrostatic treatment of Graves' disease. Clin Pharmacol Ther 2017; 102:1017-1024. 
70 Rivkees SA, Mattison DR: Ending propylthiouracil-induced liver failure in children. N Engl J Med 2009;360:1574-1575.

71 Wang MT, Lee WJ, Huang TY, Chu CL, Hsieh $\mathrm{CH}$ : Antithyroid drug-related hepatotoxicity in hyperthyroidism patients: a populationbased cohort study. Br J Clin Pharmacol 2014; 78:619-629.

72 Castro MR, Espiritu RP, Bahn RS, Henry MR, Gharib H, Caraballo PJ, Morris JC: Predictors of malignancy in patients with cytologically suspicious thyroid nodules. Thyroid 2011;21: 1191-1198.

73 Sundaresh V, Brito JP, Wang Z, Prokop LJ, Stan MN, Murad MH, Bahn RS: Comparative effectiveness of therapies for Graves' hyperthyroidism: a systematic review and network meta-analysis. J Clin Endocrinol Metab 2013; 98:3671-3677.

74 Struja T, Fehlberg H, Kutz A, Guebelin L, Degen C, Mueller B, Schuetz P: Can we predict relapse in Graves' disease? Results from a systematic review and meta-analysis. Eur J Endocrinol 2017;176:87-97.

75 Vos XG, Endert E, Zwinderman AH, Tijssen JG, Wiersinga WM: Predicting the risk of recurrence before the start of antithyroid drug therapy in patients with Graves' hyperthyroidism. J Clin Endocrinol Metab 2016;101: 1381-1389.

76 Villagelin D, Romaldini JH, Santos RB, Milkos AB, Ward LS: Outcomes in relapsed Graves' disease patients following radioiodine or prolonged low dose of methimazole treatment. Thyroid 2015;25:1282-1290.

77 Azizi F, Ataie L, Hedayati M, Mehrabi Y, Sheikholeslami F: Effect of long-term continuous methimazole treatment of hyperthyroidism: comparison with radioiodine. Eur J Endocrinol 2005;152:695-701.

78 Biondi B, Bartalena L, Cooper DS, Hegedus L, Laurberg P, Kahaly GJ: The 2015 European Thyroid Association guidelines on diagnosis and treatment of endogenous subclinical hyperthyroidism. Eur Thyroid J 2015;4:149163.

79 Collet TH, Gussekloo J, Bauer DC, den Elzen WP, Cappola AR, Balmer P, Iervasi G, Asvold BO, Sgarbi JA, Volzke H, Gencer B, Maciel RM, Molinaro S, Bremner A, Luben RN, Maisonneuve $\mathrm{P}$, Cornuz J, Newman $\mathrm{AB}$, Khaw KT, Westendorp RG, Franklyn JA, Vittinghoff E, Walsh JP, Rodondi N; Thyroid Studies Collaboration: Subclinical hyperthyroidism and the risk of coronary heart disease and mortality. Arch Intern Med 2012;172:799809.

80 Gencer B, Collet TH, Virgini V, Bauer DC, Gussekloo J, Cappola AR, Nanchen D, den Elzen WP, Balmer P, Luben RN, Iacoviello M, Triggiani V, Cornuz J, Newman AB, Khaw KT, Jukema JW, Westendorp RG, Vittinghoff E, Aujesky D, Rodondi N; Thyroid Studies Collaboration: Subclinical thyroid dysfunction and the risk of heart failure events: an individual participant data analysis from 6 prospective cohorts. Circulation 2012;126:1040-1049.
81 Wirth CD, Blum MR, da Costa BR, Baumgartner C, Collet TH, Medici M, Peeters RP, Aujesky D, Bauer DC, Rodondi N: Subclinical thyroid dysfunction and the risk for fractures: a systematic review and meta-analysis. Ann Intern Med 2014;161:189-199.

82 Blum MR, Bauer DC, Collet TH, Fink HA, Cappola AR, da Costa BR, Wirth CD, Peeters RP, Asvold BO, den Elzen WP, Luben RN, Imaizumi M, Bremner AP, Gogakos A, Eastell R, Kearney PM, Strotmeyer ES, Wallace ER, Hoff M, Ceresini G, Rivadeneira F, Uitterlinden AG, Stott DJ, Westendorp RG, Khaw KT, Langhammer A, Ferrucci L, Gussekloo J, Williams GR, Walsh JP, Juni P, Aujesky D, Rodondi N; Thyroid Studies Collaboration: Subclinical thyroid dysfunction and fracture risk: a meta-analysis. JAMA 2015;313:20552065.

83 Zhyzhneuskaya S, Addison C, Tsatlidis V, Weaver JU, Razvi S: The natural history of subclinical hyperthyroidism in Graves' disease: the rule of thirds. Thyroid 2016;26:765769.

84 Satoh T, Isozaki O, Suzuki A, Wakino S, Iburi T, Tsuboi K, Kanamoto N, Otani H, Furukawa Y, Teramukai S, Akamizu T: 2016 guidelines for the management of thyroid storm from the Japan Thyroid Association and Japan Endocrine Society (first edition). Endocr J 2016;63:1025-1064

85 Akamizu T: Thyroid storm: a Japanese perspective. Thyroid 2018;28:32-40.

86 Burch HB, Wartofsky L: Life-threatening thyrotoxicosis: thyroid storm. Endocrinol Metab Clin North Am 1993;22:263-277.

87 Akamizu T, Satoh T, Isozaki O, Suzuki A, Wakino S, Iburi T, Tsuboi K, Monden T, Kouki T, Otani H, Teramukai S, Uehara R, Nakamura Y, Nagai M, Mori M; Japan Thyroid Association: Diagnostic criteria, clinical features, and incidence of thyroid storm based on nationwide surveys. Thyroid 2012; 22:661-679.

88 Isozaki O, Satoh T, Wakino S, Suzuki A, Iburi T, Tsuboi K, Kanamoto N, Otani H, Furukawa Y, Teramukai S, Akamizu T: Treatment and management of thyroid storm: analysis of the nationwide surveys: the taskforce committee of the Japan Thyroid Association and Japan Endocrine Society for the establishment of diagnostic criteria and nationwide surveys for thyroid storm. Clin Endocrinol 2016;84:912-918.

89 Bonnema SJ, Hegedus L: Radioiodine therapy in benign thyroid diseases: effects, side effects, and factors affecting therapeutic outcome. Endocr Rev 2012;33:920-980.

90 Torring O, Tallstedt L, Wallin G, Lundell G, Ljunggren JG, Taube A, Saaf M, Hamberger B: Graves' hyperthyroidism: treatment with antithyroid drugs, surgery, or radioiodine - a prospective, randomized study. Thyroid Study Group. J Clin Endocrinol Metab 1996; 81:2986-2993.
91 In $\mathrm{H}$, Pearce EN, Wong AK, Burgess JF, McAneny DB, Rosen JE: Treatment options for Graves disease: a cost-effectiveness analysis. J Am Coll Surg 2009;209:170-179.e2.

92 Zanocco K, Heller M, Elaraj D, Sturgeon C: Is subtotal thyroidectomy a cost-effective treatment for Graves disease? A cost-effectiveness analysis of the medical and surgical treatment options. Surgery 2012;152:164-172.

93 Patel NN, Abraham P, Buscombe J, Vanderpump MP: The cost effectiveness of treatment modalities for thyrotoxicosis in a UK center. Thyroid 2006;16:593-598.

94 Donovan PJ, McLeod DS, Little R, Gordon L: Cost-utility analysis comparing radioactive iodine, anti-thyroid drugs and total thyroidectomy for primary treatment of Graves' disease. Eur J Endocrinol 2016;175:595-603.

95 Cohen RZ, Felner EI, Heiss KF, Wyly JB, Muir AB: Outcomes analysis of radioactive iodine and total thyroidectomy for pediatric Graves' disease. J Pediatr Endocrinol Metab 2016;29:319-325.

96 Sawka AM, Lakra DC, Lea J, Alshehri B, Tsang RW, Brierley JD, Straus S, Thabane L, Gafni A, Ezzat S, George SR, Goldstein DP: A systematic review examining the effects of therapeutic radioactive iodine on ovarian function and future pregnancy in female thyroid cancer survivors. Clin Endocrinol 2008;69:479-490.

97 Nygaard B, Hegedus L, Gervil M, Hjalgrim H, Hansen BM, Soe-Jensen P, Hansen JM: Influence of compensated radioiodine therapy on thyroid volume and incidence of hypothyroidism in Graves' disease. J Intern Med 1995;238:491-497.

98 Sridama V, McCormick M, Kaplan EL, Fauchet R, DeGroot LJ: Long-term follow-up study of compensated low-dose ${ }^{131}$ I therapy for Graves' disease. N Engl J Med 1984;311: 426-432.

99 Walter MA, Briel M, Christ-Crain M, Bonnema SJ, Connell J, Cooper DS, Bucher HC, Muller-Brand J, Muller B: Effects of antithyroid drugs on radioiodine treatment: systematic review and meta-analysis of randomised controlled trials. BMJ 2007;334:514.

100 Brandt F, Thvilum M, Almind D, Christensen K, Green A, Hegedus L, Brix TH: Graves' disease and toxic nodular goiter are both associated with increased mortality but differ with respect to the cause of death: a Danish population-based register study. Thyroid 2013;23:408-413.

101 Schwensen CF, Brandt F, Hegedus L, Brix TH: Mortality in Graves' orbitopathy is increased and influenced by gender, age and pre-existing morbidity: a nationwide Danish register study. Eur J Endocrinol 2017;176: 669-676.

102 Lillevang-Johansen M, Abrahamsen B, Jorgensen HL, Brix TH, Hegedus L: Excess mortality in treated and untreated hyperthyroidism is related to cumulative periods of low serum TSH. J Clin Endocrinol Metab 2017;102:2301-2309. 
103 Ron E, Doody MM, Becker DV, Brill AB, Curtis RE, Goldman MB, Harris BS 3rd, Hoffman DA, McConahey WM, Maxon HR, Preston-Martin S, Warshauer ME, Wong FL, Boice JD Jr: Cancer mortality following treatment for adult hyperthyroidism. Cooperative Thyrotoxicosis Therapy Follow-up Study Group. JAMA 1998;280:347-355.

104 Bonnema SJ, Bennedbaek FN, Veje A, Marving J, Hegedus L: Propylthiouracil before ${ }^{131} \mathrm{I}$ therapy of hyperthyroid diseases: effect on cure rate evaluated by a randomized clinical trial. J Clin Endocrinol Metab 2004;89: 4439-4444.

105 Bonnema SJ, Bennedbaek FN, Gram J, Veje A, Marving J, Hegedus L: Resumption of methimazole after ${ }^{131}$ I therapy of hyperthyroid diseases: effect on thyroid function and volume evaluated by a randomized clinical trial. Eur J Endocrinol 2003;149:485-492.

106 Bartalena L, Marcocci C, Bogazzi F, Panicucci M, Lepri A, Pinchera A: Use of corticosteroids to prevent progression of Graves' ophthalmopathy after radioiodine therapy for hyperthyroidism. N Engl J Med 1989;321: 1349-1352.

107 Jensen BE, Bonnema SJ, Hegedus L: Glucocorticoids do not influence the effect of radioiodine therapy in Graves' disease. Eur J Endocrinol 2005;153:15-21.

108 Burch HB, Burman KD, Cooper DS: A 2011 survey of clinical practice patterns in the management of Graves' disease. J Clin Endocrinol Metab 2012;97:4549-4558.

109 Bartalena L, Chiovato L, Vitti P: Management of hyperthyroidism due to Graves' disease: frequently asked questions and answers (if any). J Endocrinol Invest 2016;39: 1105-1114.

110 Genovese BM, Noureldine SI, Gleeson EM, Tufano RP, Kandil E: What is the best definitive treatment for Graves' disease? A systematic review of the existing literature. Ann Surg Oncol 2013;20:660-667.

111 Guo Z, Yu P, Liu Z, Si Y, Jin M: Total thyroidectomy vs bilateral subtotal thyroidectomy in patients with Graves' diseases: a meta-analysis of randomized clinical trials. Clin Endocrinol 2013;79:739-746.

112 Sosa JA, Bowman HM, Tielsch JM, Powe NR, Gordon TA, Udelsman R: The importance of surgeon experience for clinical and economic outcomes from thyroidectomy. Ann Surg 2008;228:320-330.

113 Erbil Y, Ozluk Y, Giris M, Salmaslioglu A, Issever H, Barbaros U, Kapran Y, Ozarmagan S, Tezelman S: Effect of lugol solution on thyroid gland blood flow and microvessel density in the patients with Graves' disease. J Clin Endocrinol Metab 2007;92:21822189.

114 Edafe O, Antakia R, Laskar N, Uttley L, Balasubramanian SP: Systematic review and meta-analysis of predictors of post-thyroidectomy hypocalcaemia. Br J Surg 2014;101: 307-320.
115 Bartalena L, Baldeschi L, Boboridis K, Eckstein A, Kahaly GJ, Marcocci C, Perros P, Salvi M, Wiersinga WM; European Group on Graves Orbitopathy: The 2016 European Thyroid Association/European Group on Graves' Orbitopathy guidelines for the management of Graves' orbitopathy. Eur Thyroid J 2016;5:9-26.

116 Bartalena L, Macchia PE, Marcocci C, Salvi $\mathrm{M}$, Vermiglio F: Effects of treatment modalities for Graves' hyperthyroidism on Graves' orbitopathy: a 2015 Italian Society of Endocrinology Consensus Statement. J Endocrinol Invest 2015;38:481-487.

117 Bartalena L: The dilemma of how to manage Graves' hyperthyroidism in patients with associated orbitopathy. J Clin Endocrinol Metab 2011;96:592-599.

118 Laurberg P, Wallin G, Tallstedt L, AbrahamNordling M, Lundell G, Torring O: TSH-receptor autoimmunity in Graves' disease after therapy with anti-thyroid drugs, surgery, or radioiodine: a 5-year prospective randomized study. Eur J Endocrinol 2008;158: 69-75.

119 Bartalena L, Marcocci C, Bogazzi F, Manetti L, Tanda ML, Dell'Unto E, Bruno-Bossio G, Nardi M, Bartolomei MP, Lepri A, Rossi G, Martino E, Pinchera A: Relation between therapy for hyperthyroidism and the course of Graves' ophthalmopathy. N Engl J Med 1998;338:73-78.

120 Karlsson F, Dahlberg P, Jansson R, Westermark K, Enoksson P: Importance of TSH receptor activation in the development of severe endocrine ophthalmopathy. Acta Endocrinol 1989;121(suppl 2):132-141.

121 Bartalena L, Marcocci C, Bogazzi F, Panicucci M, Lepri A, Pinchera A: Use of corticosteroids to prevent progression of Graves' ophthalmopathy after radioiodine therapy for hyperthyroidism. N Engl J Med 1989;321: 1349-1352.

122 Tallstedt L, Lundell G, Torring O, Wallin G, Ljunggren JG, Blomgren $\mathrm{H}$, Taube A: Occurrence of ophthalmopathy after treatment for Graves' hyperthyroidism. The Thyroid Study Group. N Engl J Med 1992;326:17331738.

123 Traisk F, Tallstedt L, Abraham-Nordling M, Andersson T, Berg G, Calissendorff J, Hallengren B, Hedner P, Lantz M, Nystrom E, Ponjavic V, Taube A, Torring O, Wallin G, Asman P, Lundell G; Thyroid Study Group of TT 96: Thyroid-associated ophthalmopathy after treatment for Graves' hyperthyroidism with antithyroid drugs or iodine-131. J Clin Endocrinol Metab 2009;94: 3700-3707.

124 Vannucchi G, Campi I, Covelli D, Dazzi D, Curro N, Simonetta S, Ratiglia R, Beck-Peccoz P, Salvi M: Graves' orbitopathy activation after radioactive iodine therapy with and without steroid prophylaxis. J Clin Endocrinol Metab 2009;94:3381-3386.
125 Tallstedt L, Lundell G, Blomgren H, Bring J: Does early administration of thyroxine reduce the development of Graves' ophthalmopathy after radioiodine treatment? Eur J Endocrinol 1994;130:494-497.

126 Perros P, Kendall-Taylor P, Neoh C, Frewin S, Dickinson J: A prospective study of the effects of radioiodine therapy for hyperthyroidism in patients with minimally active Graves' ophthalmopathy. J Clin Endocrinol Metab 2005;90:5321-5323.

127 Kung AW, Yau CC, Cheng A: The incidence of ophthalmopathy after radioiodine therapy for Graves' disease: prognostic factors and the role of methimazole. J Clin Endocrinol Metab 1994;79:542-546.

128 Lai A, Sassi L, Compri E, Marino F, Sivelli P, Piantanida E, Tanda ML, Bartalena L: Lower dose prednisone prevents radioiodine-associated exacerbation of initially mild or absent Graves' orbitopathy: a retrospective cohort study. J Clin Endocrinol Metab 2010 95:1333-1337.

129 Acharya SH, Avenell A, Philip S, Burr J, Bevan JS, Abraham P: Radioiodine therapy (RAI) for Graves' disease (GD) and the effect on ophthalmopathy: a systematic review. Clin Endocrinol 2008;69:943-950.

130 Shiber S, Stiebel-Kalish H, Shimon I, Grossman A, Robenshtok E: Glucocorticoid regimens for prevention of Graves' ophthalmopathy progression following radioiodine treatment: systematic review and meta-analysis. Thyroid 2014;24:1515-1523.

131 Marcocci C, Bruno-Bossio G, Manetti L, Tanda ML, Miccoli P, Iacconi P, Bartolomei MP, Nardi M, Pinchera A, Bartalena L: The course of Graves' ophthalmopathy is not influenced by near total thyroidectomy: a casecontrol study. Clin Endocrinol 1999;51:503508.

132 Marcocci C, Kahaly GJ, Krassas GE, Bartalena L, Prummel M, Stahl M, Altea MA, Nardi M, Pitz S, Boboridis K, Sivelli P, von Arx G, Mourits MP, Baldeschi L, Bencivelli W, Wiersinga W; European Group on Graves Orbitopathy: Selenium and the course of mild Graves' orbitopathy. N Engl J Med 2011;364: 1920-1931.

133 Bartalena L, Tanda ML: Clinical practice: Graves' ophthalmopathy. N Engl J Med 2009;360:994-1001.

134 Krassas GE, Poppe K, Glinoer D: Thyroid function and human reproductive health. Endocr Rev 2010;31:702-755.

135 Andersen SL, Olsen J, Carle A, Laurberg P. Hyperthyroidism incidence fluctuates widely in and around pregnancy and is at variance with some other autoimmune diseases: a Danish population-based study. J Clin Endocrinol Metab 2015;100:1164-1171.

136 Laurberg P, Bournaud C, Karmisholt J, Orgiazzi J: Management of Graves' hyperthyroidism in pregnancy: focus on both maternal and foetal thyroid function, and caution against surgical thyroidectomy in pregnancy. Eur J Endocrinol 2009;160:1-8. 
137 Andersen SL, Olsen J, Laurberg P: Antithyroid drug side effects in the population and in pregnancy. J Clin Endocrinol Metab 2016; 101:1606-1614.

138 Alexander EK, Larsen PR: High dose of ${ }^{131}$ I therapy for the treatment of hyperthyroidism caused by Graves' disease. J Clin Endocrinol Metab 2002;87:1073-1077.

139 Nicholas WC, Fischer RG, Stevenson RA, Bass JD: Single daily dose of methimazole compared to every 8 hours propylthiouracil in the treatment of hyperthyroidism. South Med J 1995;88:973-976.

140 Nakamura H, Noh JY, Itoh K, Fukata S, Miyauchi A, Hamada N: Comparison of methimazole and propylthiouracil in patients with hyperthyroidism caused by Graves' disease. J Clin Endocrinol Metab 2007;92: 2157-2162.

141 Korelitz JJ, McNally DL, Masters MN, Li SX, $\mathrm{Xu}$ Y, Rivkees SA: Prevalence of thyrotoxicosis, antithyroid medication use, and complications among pregnant women in the United States. Thyroid 2013;23:758-765.

142 Andersen SL, Olsen J, Wu CS, Laurberg P: Birth defects after early pregnancy use of antithyroid drugs: a Danish nationwide study. J Clin Endocrinol Metab 2013;98:43734381.

143 Rubin PC: Current concepts: beta-blockers in pregnancy. N Engl J Med 1981;305:13231326.

144 Momotani N, Hisaoka T, Noh J, Ishikawa N, Ito K: Effects of iodine on thyroid status of fetus versus mother in treatment of Graves' disease complicated by pregnancy. J Clin Endocrinol Metab 1992;75:738-744.

145 Nedrebo BG, Holm PI, Uhlving S, Sorheim JI, Skeie S, Eide GE, Husebye ES, Lien EA, Aanderud S: Predictors of outcome and comparison of different drug regimens for the prevention of relapse in patients with Graves' disease. Eur J Endocrinol 2002;147: 583-589.

146 Laurberg P, Andersen SL: Therapy of endocrine disease: antithyroid drug use in early pregnancy and birth defects: time windows of relative safety and high risk? Eur J Endocrinol 2014;171:R13-R20.
147 Laurberg P: Remission of Graves' disease during anti-thyroid drug therapy: time to reconsider the mechanism? Eur J Endocrinol 2006;155:783-786.

148 Bliddal S, Rasmussen AK, Sundberg K, Brocks V, Feldt-Rasmussen U: Antithyroid drug-induced fetal goitrous hypothyroidism. Nat Rev Endocrinol 2011;7:396-406.

149 McKenzie JM, Zakarija M: Fetal and neonatal hyperthyroidism and hypothyroidism due to maternal TSH receptor antibodies. Thyroid 1992;2:155-159.

150 Abeillon-du Payrat J, Chikh K, Bossard N, Bretones P, Gaucherand P, Claris O, Charrie A, Raverot V, Orgiazzi J, Borson-Chazot F, Bournaud C: Predictive value of maternal second-generation thyroid-binding inhibitory immunoglobulin assay for neonatal autoimmune hyperthyroidism. Eur J Endocrinol 2014;171:451-460.

151 Cove DH, Johnston P: Fetal hyperthyroidism: experience of treatment in four siblings. Lancet 1985; 1:430-432.

152 Amino N, Tanizawa O, Mori H, Iwatani Y, Yamada T, Kurachi K, Kumahara Y, Miyai K: Aggravation of thyrotoxicosis in early pregnancy and after delivery in Graves' disease. J Clin Endocrinol Metab 1982;55:108-112.

153 Alexander EK, Pearce EN, Brent GA, Brown RS, Chen H, Dosiou C, Grobman WA, Laurberg P, Lazarus JH, Mandel SJ, Peeters RP, Sullivan S: 2017 guidelines of the American Thyroid Association for the Diagnosis and Management of Thyroid Disease During Pregnancy and the Postpartum. Thyroid 2017;27:315-389.

154 Mandel SJ, Cooper DS: The use of antithyroid drugs in pregnancy and lactation. J Clin Endocrinol Metab 2001;86:2354-2359.

155 Pearce SH: Spontaneous reporting of adverse reactions to carbimazole and propylthiouracil in the UK. Clin Endocrinol 2004; 61:589-594

156 Perros P, Crombie AL, Matthews JN, Kendall-Taylor P: Age and gender influence the severity of thyroid-associated ophthalmopathy: a study of 101 patients attending a combined thyroid-eye clinic. Clin Endocrinol 1993;38:367-372.
157 Leger J, Gelwane G, Kaguelidou F, Benmerad M, Alberti C; French Childhood Graves' Disease Study Group: Positive impact of long-term antithyroid drug treatment on the outcome of children with Graves' disease: national long-term cohort study. J Clin Endocrinol Metab 2012;97: 110-119.

158 Ohye H, Minagawa A, Noh JY, Mukasa K, Kunii Y, Watanabe N, Matsumoto M, Suzuki M, Yoshihara A, Ito K, Ito K: Antithyroid drug treatment for graves' disease in children: a long-term retrospective study at a single institution. Thyroid 2014;24:200207.

159 Rivkees SA, Szarfman A: Dissimilar hepatotoxicity profiles of propylthiouracil and methimazole in children. J Clin Endocrinol Metab 2010;95:3260-3267.

160 Ma C, Kuang A, Xie J, Liu G: Radioiodine treatment for pediatric Graves' disease. Cochrane Database Syst Rev 2008;3:CD006294.

161 Coles AJ, Wing M, Smith S, Coraddu F, Greer S, Taylor C, Weetman A, Hale G, Chatterjee VK, Waldmann $\mathrm{H}$, Compston A: Pulsed monoclonal antibody treatment and autoimmune thyroid disease in multiple sclerosis. Lancet 1999;354:1691-1695.

162 Chen F, Day SL, Metcalfe RA, Sethi G, Kapembwa MS, Brook MG, Churchill D, de Ruiter A, Robinson S, Lacey CJ, Weetman AP: Characteristics of autoimmune thyroid disease occurring as a late complication of immune reconstitution in patients with advanced human immunodeficiency virus (HIV) disease. Medicine 2005;84:98-106.

163 Weetman AP: Graves' disease following immune reconstitution or immunomodulatory treatment: should we manage it any differently? Clin Endocrinol 2014;80:629-632.

164 Furmaniak J, Sanders J, Nunez Miguel R, Rees Smith B: Mechanisms of action of TSHR autoantibodies. Horm Metab Res 2015;47:735-752.

165 Gershengorn MC, Neumann S: Update in TSH receptor agonists and antagonists. J Clin Endocrinol Metab 2012;97:4287-4292.

166 El Fassi D, Nielsen CH, Hasselbalch HC, Hegedus L: The rationale for B lymphocyte depletion in Graves' disease: monoclonal anti-CD20 antibody therapy as a novel treatment option. Eur J Endocrinol 2006; 154:623-632. 